\title{
Bayesian Networks for Modeling Dredging Decisions
}

Martin T. Schultz, Thomas D. Borrowman,

October 2011 and Mitchell J. Small

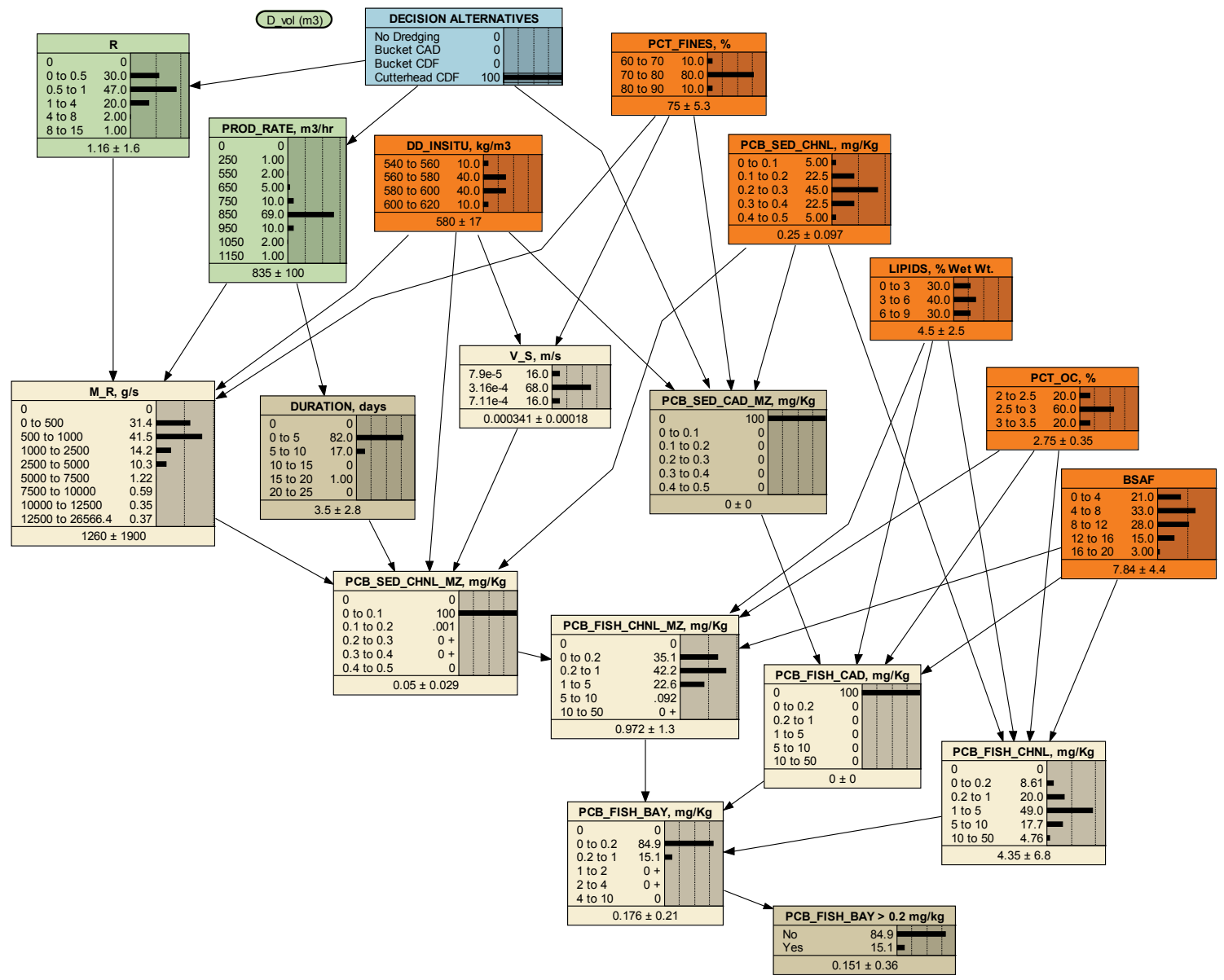


ERDC/EL TR-11-14

October 2011

\title{
Bayesian Networks for Modeling Dredging Decisions
}

\author{
Martin T. Schultz and Thomas D. Borrowman \\ Environmental Laboratory \\ U.S. Army Engineer Research and Development Center \\ 3909 Halls Ferry Road \\ Vicksburg, MS 39180-6199 \\ Mitchell J. Small \\ Department of Civil and Environmental Engineering and Department of Engineering and Public Policy \\ Carnegie Mellon University \\ 5000 Forbes Avenue \\ Pittsburgh, PA 15213-3890
}

Final report

Approved for public release; distribution is unlimited.

Prepared for U.S. Army Corps of Engineers

Washington, DC 20314-1000 


\begin{abstract}
This report introduces Bayesian networks and describes how they can be used to model dredging decisions when uncertainties are present. Bayesian networks are efficient representations of joint probability distributions that can be used to perform statistical inference over a large number of random variables. An example application is developed and presented for a realistic estuarine dredging decision problem to demonstrate the method. The decision model is applied to analyze the value of obtaining additional information about selected variables that are sources of uncertainty in the decision.
\end{abstract}

DISCLAIMER: The contents of this report are not to be used for advertising, publication, or promotional purposes. Citation of trade names does not constitute an official endorsement or approval of the use of such commercial products. All product names and trademarks cited are the property of their respective owners. The findings of this report are not to be construed as an official Department of the Army position unless so designated by other authorized documents. 


\section{Contents}

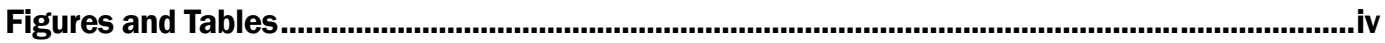

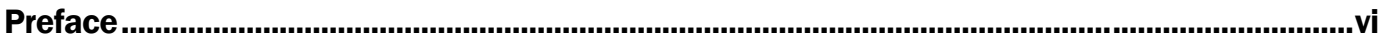

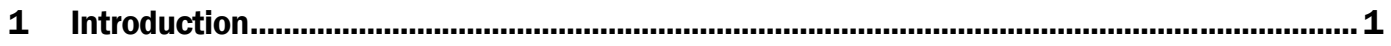

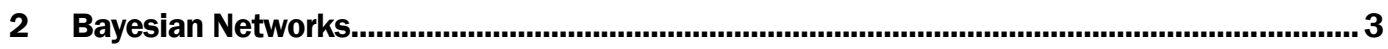

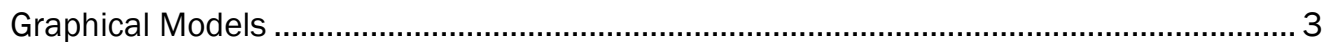

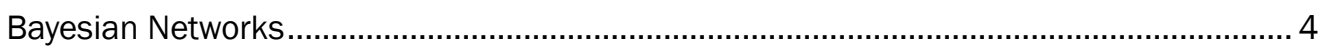

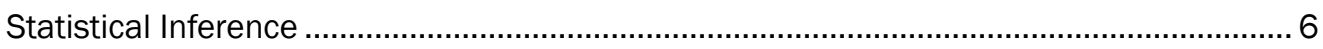

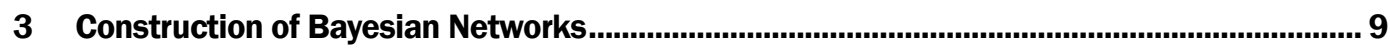

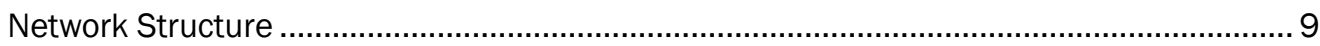

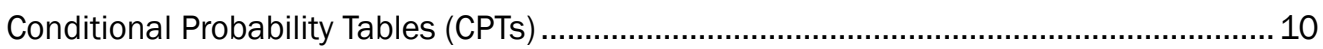

Best Practices for Constructing Bayesian Network Models .............................................. 11

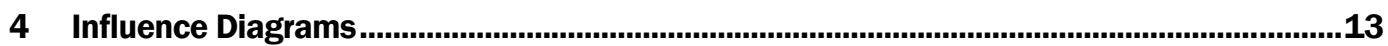

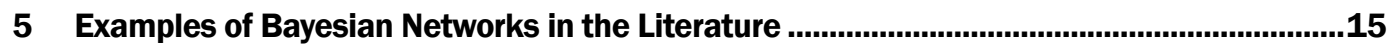

6 Dredging Decision Models ..........................................................................................

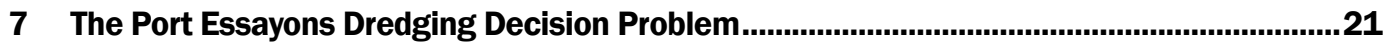

The Port Essayons Decision Model ........................................................................... 22

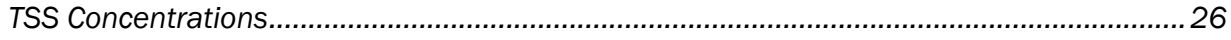

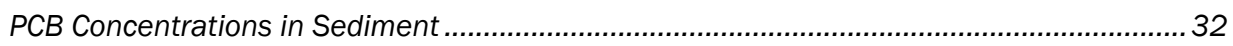

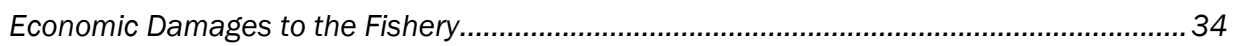

Dredging Cost (OP_COST_TOTAL) .................................................................................

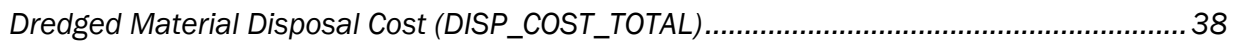

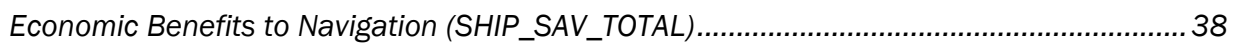

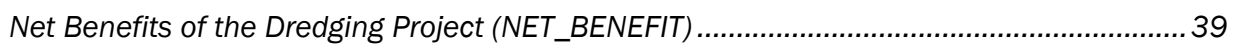

Evaluation of Dredging and Dredged Material Disposal Alternatives .....................................39

8 Statistical Inference and Value of Information Analysis .................................................41

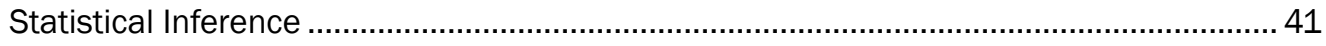

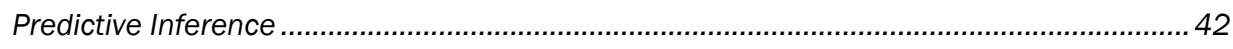

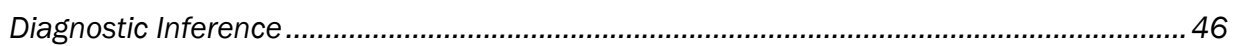

Value of Information (VOI) Analysis ............................................................................. 47

Value of Information in the Port Essayons Decision Model.............................................49

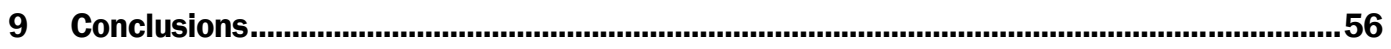

References..........................................................................................................................60 


\section{Figures and Tables}

\section{Figures}

Figure 1: A graphical model and its corresponding Bayesian network. The graphical model consists of five nodes and five directed edges (a). The fully parameterized Bayesian network corresponds to the graphical model (b).

Figure 2. Instantiation of a Bayesian network. Instantiation of node X2 for predictive inference (a) and instantiation of node X5 for diagnostic inference (b).

Figure 3. An influence diagram consisting of five chance nodes, one decision node, and one utility node.

Figure 4. Port Essayons estuary. The figure shows the location of the navigation channel section to be dredged, the CAD pit, the CDF, and the mixing zones. Dashed lines denote the boundaries of the mixing zones for the CAD pit, CDF, and dredge plume. Bidirectional arrows indicate the direction of tidal flow paths in an out of the estuary...

Figure 5. Decision model for selecting dredging equipment and dredged material placement alternatives in Port Essayons' estuary.

Figure 6. Subset of the decision model used for demonstration of statistical inference and VOI analysis. The No_Dredging alternative is instantiated to show the baseline probability of exceeding the regulatory limit of $0.2 \mathrm{mg} / \mathrm{kg}$ of PCBs in fish tissue.

Figure 7. Subset of the decision model showing instantiation of the Cutterhead_CDF alternative. Cutterhead_CDF is instantiated to show how the probability of exceeding the maximum allowable concentration of PCBs in fish tissue would change relative to the baseline conditions.

Figure 8. Predictive inference with instantiation of the LIPIDS node.

Figure 9. Predictive inference with instantiation of the LIPIDS and PCT_OC nodes......................... 45

Figure 10. Diagnostic inference with instantiation of the PCB_FISH_BAY node.

Figure 11. A Bayesian network for the determinants of PCB concentrations in bay fish. The model estimates the probability that fish tissue concentrations will exceed $0.2 \mathrm{mg} / \mathrm{kg}$. The network is shown with prior uncertainties and Cutterhead_CDF is chosen as the dredging alternative.

Figure 12. VOI analysis for LIPIDS. The black line (with solid white circles) shows the probability that a perfect study will cause the preferred decision alternative to switch. Also shown are the preferred decision alternative $(0=$ Do Not Dredge; $1=$ Dredge $)$ under the prior uncertainty (solid blue line) and with fixed values of the LIPIDS (dashed lines) as a function of the allowable projected probability that PCBs in bay fish will be $>0.2 \mathrm{mg} / \mathrm{kg}$.

Figure 13. VOI analysis for BSAF. The black line (with solid white circles) shows the probability that a perfect study will cause the preferred decision alternative to switch. Also shown are the preferred decision alternative $(0=$ Do Not Dredge; $1=$ Dredge $)$ under the prior uncertainty (solid blue line) and with fixed values of the BSAF (dashed lines) as a function of the allowable projected probability that PCBs in bay fish will be $>0.2 \mathrm{mg} / \mathrm{kg}$.. 


\section{Tables}

Table 1. Bayesian network applications reviewed in the literature. ................................................... 16

Table 2. A summary of the potential environmental impacts of dredging operations....................... 19

Table 3. SDN, SCN and EFN that were parameterized using data, model outputs, or engineering judgment. Nodes parameterized using equations are described in the text.................2 27

Table 4. Fixed parameter values used in the DREDGE model.........................................................30

Table 5. Fixed parameter values used in the STFATE model.............................................................. 31

Table 6. Fixed parameter values used in the SETTLE model. ............................................................32

Table 7. Index for assessing suspended sediment impacts on fish. ..................................................36

Table 8. Expected NET_BENEFIT of the alternatives. ……............................................................... 40

Table 9. Predicted Prob[PCB_FISH_BAY > 0.2 mg/kg] ................................................................ 51

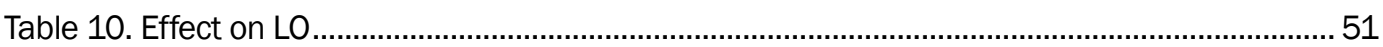

Table 11. Change in LO(Prob[PCB_FISH_BAY>0.2mg/kg]) relative to prior. ..................................52 


\section{Preface}

This report introduces the use of discrete Bayesian networks as an approach to decision making under uncertainty. An example is developed to demonstrate the decision-modeling approach for a navigation dredging decision. Preparation and publication of this report was sponsored by the U.S. Army Corps of Engineers (USACE) Dredging Operations Environmental Research (DOER) Program, Focus Area: Risk.

This report was written by Dr. Martin T. Schultz, Environmental Risk Assessment Branch, Environmental Processes and Engineering Division (EPED), Environmental Laboratory (EL); Thomas D. Borrowman, Environmental Engineering Branch, EPED, EL; and Dr. Mitchell J. Small, Department of Civil and Environmental Engineering and Department of Engineering and Public Policy, Carnegie Mellon University. The authors wish to thank Dr. Paul R. Schroeder for comments and discussions on modeling of dredging activities. Dr. Andrew F. Casper of the Aquatic Ecology and Invasive Species Branch, Ecosystem Evaluation and Engineering Division, EL, and Dr. Kenneth N. Mitchell, Coastal Engineering Branch, Navigation Division, Coastal and Hydraulics Laboratory, reviewed this report and provided comments and suggestions to improve the report.

This report was written under the direct supervision of Beth Fleming, Director, EL, Warren P. Lorentz, Chief, Environmental Processes and Engineering Division, EL, William T. Jones, Acting Chief, Environmental Risk Assessment Branch, EL, and Todd Bridges, Program Manager.

COL Kevin J. Wilson was Commander of the ERDC. Dr. Jeffery P. Holland was Director of the ERDC. 


\section{Introduction}

The role of the U.S. Army Corps of Engineers (USACE) with respect to navigation is to provide safe, reliable, and efficient waterborne transportation systems (channels, harbors, and waterways) for movement of commerce, national security needs, and recreation. The USACE accomplishes this mission through a combination of capital improvements and the operation and maintenance of existing projects. The economic benefits of navigation projects may be offset by dredging project costs and environmental impacts at the dredging site. While the potential environmental impacts of dredging are well known, the environmental outcomes at any particular dredging site tend to be highly uncertain (PIANC 2009). This uncertainty arises from incomplete knowledge and natural variability in the conditions at a dredging project site, and incomplete knowledge about the physical, chemical, and biological processes governing those conditions.

Uncertainty about the potential environmental impacts of a proposed dredging project can lead to stakeholder conflicts, lengthy and costly project delays, and costly restrictions on the dredging project, including restrictions on the timing of dredging operations and the methods used to accomplish project objectives (Reine, Dickerson and Clarke 1998). Risk-informed approaches to decision making can be employed to increase the efficiency of dredging projects by analyzing the probability of potential economic and environmental outcomes. The decision modeling approach described in this technical report provides a practical and broadly applicable means to implement risk-informed decision making within the navigation business line and could readily be extended to other business lines.

A decision is an action that leads to an allocation of resources or an outcome that is irrevocable or nearly so because it would be very costly to restore the allocation that existed prior to the action (Howard 1966). The term decision analysis was coined by Howard (1966) to describe a logical procedure for the balancing of the factors that influence a decision when the outcomes are uncertain. The procedure arises from a merging of systems engineering methods and statistical decision theory, which is the study of how individuals make decisions when faced with a choice that has an uncertain outcome or involves multiple conflicting objectives (von Winterfeldt and Edwards 2007). 
In practical applications of decision analysis, the objective is to develop a structural model of the decision that includes specific references to sources of uncertainty and to a decision maker's objectives, alternatives, and preferences. Thus, decision models differ from bio-physical and engineering models - such as hydrologic models or fate and transport models although they may incorporate such models as components. The nominal purpose of a decision model is to identify an alternative course of action that maximizes the decision maker's expected net-benefit and assess the robustness of an alternative in the face of uncertainty and conflicting value systems. Decision models also help decision makers to identify the most important drivers in a decision, evaluate controversies among stakeholders, update decisions as new information becomes available, and evaluate opportunities to obtain better information before making a decision.

This technical report introduces Bayesian networks and demonstrates how they can be structured and parameterized to model dredging decisions that have uncertain environmental outcomes. An example decision model is developed for a realistic dredging decision problem to demonstrate the approach. Statistical inference and value of information (VOI) analysis are demonstrated using a subset of the decision model. 


\section{Bayesian Networks}

Bayesian networks provide an efficient way to address a large number of uncertainties in the decision making process. A Bayesian network consists of two parts. The first part is a graphical structure that captures qualitative knowledge about how the components of the system are related and the second part is a set of conditional probability tables (CPTs) that quantify the relationships between the variables that are represented in the network. The prior conditional probabilities in a network reflect engineering judgment, the outputs of models, or data from either the system of interest or similar systems. Random variables may assume any number of states and the probability of a variable being in any one state is conditioned on the state of its parent nodes. Random variables may be either discrete or continuous; however, Bayesian networks have traditionally assumed discrete random variables. This may be attributed to the fact that algorithms for solving the discrete case preceded those for solving the continuous case. This introduction to Bayesian networks addresses the discrete case.

\section{Graphical Models}

In general, a graph is a data structure consisting of a set of nodes, $\left\{X_{i}, \ldots X_{j}\right.$, $\left.\ldots, X_{n}\right\}$ and a set of edges that link nodes. A pair of nodes may be linked by directed edges $X_{i} \rightarrow X_{j}$ or $X_{j} \rightarrow X_{i}$, or by undirected edges $X_{i}-X_{j}$ (Koller and Friedman 2009). Given a pair of nodes $X_{i} \rightarrow X_{j}, X_{i}$ is called the parent node and $X_{j}$ is called the child node. The parent is the node from which a directed edge emanates and the child is the node to which the edge is directed. A graph is called a directed acyclic graph (DAG) if all edges are directed and no path exists within the graph from any parent node leading back to that parent node in the direction of the edges. The nodes of a DAG represent well-defined elements in a system of interest about which we may have knowledge (information) and the directed edges between nodes indicate the dependence and independence relationships among elements of that system. For example, Figure 1(a) shows a graphical model that illustrates the dependence and independence relationships among five elements of a system $\left(X_{1}, X_{2}, X_{3}, X_{4}\right.$, and $\left.X_{5}\right)$. 


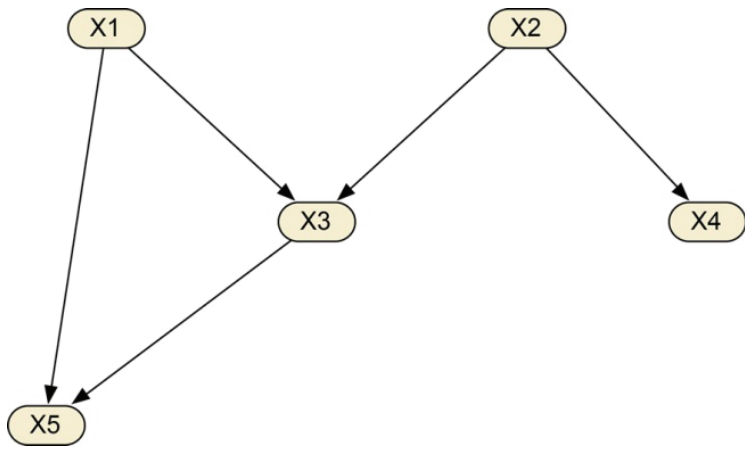

(a)

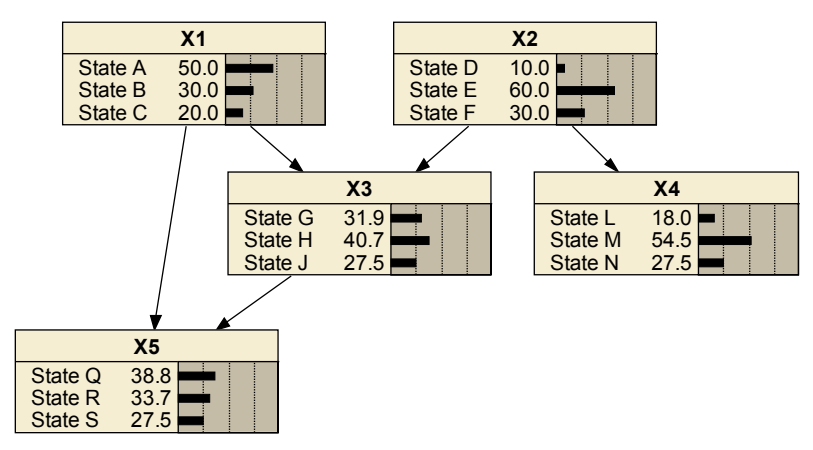

(b)

Figure 1: A graphical model and its corresponding Bayesian network. The graphical model consists of five nodes and five directed edges (a). The fully parameterized Bayesian network corresponds to the graphical model (b).

The dependence and independence relationships in Figure 1 are as follows. Nodes $X_{3}$ and $X_{5}$ are directly dependent upon $X_{1}$. Nodes $X_{3}$ and $X_{4}$ are directly dependent upon $X_{2}$. The absence of a directed edge between two nodes indicates conditional independence. For example, nodes $X_{1}$ and $X_{2}$ and nodes $X_{2}$ and $X_{5}$ are conditionally independent. The graphical structure of a network itself provides an intuitive representation of the dependence and independence relationships among nodes in a system and offers an excellent means for communicating and discussing those relationships. However, by itself, the graph is not a powerful analytical model. The graph provides a framework for modeling the system that is represented by quantifying the relationships between the nodes of the network as shown in Figure 1(b) and discussed below.

\section{Bayesian Networks}

A fully parameterized Bayesian network is a DAG in which the nodes represent random variables, the edges signify the existence of influence between linked variables, and the strengths of these influences are expressed by forward conditional probabilities (Pearl 1988). Figure 1(b) illustrates a fully parameterized Bayesian network. The Bayesian network describes a factorization of the joint probability distribution over the random variables, where the factorization is given by the structure of the network. In general, the factorization of the joint probability distribution can be written:

$$
P\left(X_{1}, X_{2}, \ldots, X_{n}\right)=\prod_{i=1}^{n} P\left(X_{i} \mid X_{p a(i)}\right)
$$


where the notation $p a(i)$ means $X$ is a parent of node $i$ and the notation $P\left(X_{i} \mid X_{p a(i)}\right)$ means the probability that $X$ is in state $i$ given the state of parent nodes. Nodes with parents are defined by CPTs that give, for every possible state of the variable, a probability of being in that state given the state of all parent node variables. Parentless nodes, which are called roots, are parameterized by marginal probability distributions.

There are two types of dependence relationships in a DAG: Direct dependence and conditional independence. A node (the child) is directly dependent upon another node (the parent) if there is a directed edge linking the parent directly to the child. Influence or information flows in the direction of the edge. In this case, child node probabilities may be determined by knowing only the states of the parent nodes. A node is conditionally independent of another node if there is no directed edge directly linking that node to the other, but there is a pathway between the two nodes (not necessarily in the direction of the edge). A node is conditionally independent of another node if, given perfect information about all of its parents, it is unaffected by knowledge of the other node. Complete independence of one node on another node is rare in Bayesian networks (Reckhow 1999).

There are three kinds of connections among variables within a DAG: the serial connection, the diverging connection, and the converging connection (Wilson and Huzurbazar 2007, Kjaerulff and Madsen 2008). In Figure 1(b), a serial connection exists between nodes $X_{2}, X_{3}$, and $X_{5}\left(X_{2} \rightarrow X_{3} \rightarrow X_{5}\right)$. Information can only be transmitted through a serial connection, from $X_{2}$ to $X_{5}$, if the state of node $X_{3}$ is uncertain. The joint probability of the node states is:

$$
P\left(X_{2}, X_{3}, X_{5}\right)=P\left(X_{5} \mid X_{3}\right) P\left(X_{3} \mid X_{2}\right) P\left(X_{2}\right)
$$

A diverging connection is illustrated by nodes $X_{2}, X_{3}$, and $X_{4}\left(X_{3} \leftarrow X_{2} \rightarrow X_{4}\right)$. Information can only be transmitted through a diverging connection, between $X_{2}$ and $X_{4}$, if the state of node $X_{3}$ is uncertain. The joint probability is calculated:

$$
P\left(X_{2}, X_{3}, X_{4}\right)=P\left(X_{3} \mid X_{2}\right) P\left(X_{4} \mid X_{2}\right) P\left(X_{2}\right)
$$

A converging connection is illustrated by nodes $X_{1}, X_{2}$, and $X_{3}$ $\left(X_{1} \rightarrow X_{3} \leftarrow X_{2}\right)$. Information is only transmitted through a converging 
connection if the state of node $X_{3}$ or one of its descendents is known. The joint probability is calculated:

$$
P\left(X_{1}, X_{2}, X_{3}\right)=P\left(X_{3} \mid X_{1}, X_{2}\right) P\left(X_{1}\right) P\left(X_{2}\right)
$$

Pearl (1988) developed the concepts of $d$-separation and $d$-connection to indicate whether one node is dependent on another node given information about a third node (Kjaerulff and Madsen 2008). For example, in Figure 1(b), information may be transmitted from node $X_{2}$ to node $X_{5}$ via node $X_{3}$. Whether or not node $X_{2}$ influences our beliefs about node $X_{3}$ depends on what information we have on node $\mathrm{X}_{3}$. Two nodes are $d$-separated if no information can be transmitted from one node to the other node given information about the third node. Two nodes are $d$-connected if information can be transmitted. As discussed above, whether or not information can be transmitted between nodes depends upon the nature of the pathways between nodes (serial, diverging, or converging) and whether or not information is available about intermediate nodes.

\section{Statistical Inference}

While representation of dependence and independence relationships is a useful feature for communication, the greater value in Bayesian networks is in their ability to perform statistical inference. The computational demands of inference about a joint probability distribution can be extremely high. These demands are directly related to the number of random variables and states in a network as well as the overall structure of the network - in other words, how the nodes are connected to one another (Koller and Friedman 2009). It is only relatively recently, within the past twenty-five years, that algorithms have been developed to solve these problems efficiently. Most modern Bayesian network software uses junction tree (a.k.a. join tree) algorithms developed by Lauritzen and Spiegelhalter (1988) and Jensen et al. (1990). Statistical inference is simply the process of probabilistic reasoning about the modeled system. Statistical inference can be classified as either predictive (causal) or diagnostic (evidential) (Kjaerulff and Madsen 2008, Koller and Friedman 2009).

In predictive applications, the objective is to reason from cause to effect and assess the probability of a particular outcome given knowledge about the state of ancestral nodes. The ability to solve predictive inference problems is particularly useful when dealing with complex systems about 
which understanding of causal effects is limited or direct observations of system states are difficult. In such cases, the state of the system must be inferred from uncertain information about site conditions.

Diagnostic inference is reasoning from effects to causes and the objective is to predict the probability that an ancestor node is in a particular state given evidence about the descendent node. When there are multiple possible causes for an effect, this form of reasoning can be used to predict the probabilities of potential causes, a process known as explaining away. The ability to explain away the causes of an effect is unique to Bayesian networks and is made possible by the presence of converging connections (Kjaerulff and Madsen 2008).

Inference is accomplished by first applying information to the model in the form of hard evidence or soft evidence. Hard evidence is knowledge that a particular variable is in a particular state and that the probability of being in all of the other possible states is zero. Entering hard evidence is called instantiation (Kjaerulff and Madsen 2008). Soft evidence is uncertain knowledge about a variable. If soft evidence is available about a variable, the probabilities that are coded in that variable node can be updated by entering a finding in the form of a probability distribution. When hard or soft evidence is entered into a node to reflect observations about a variable in the system, the objective is to compute the posterior probabilities for all the nodes in the network. The posterior probability $Y$ is simply the probability that $Y$ is in a particular state given the observations or evidence about other nodes, $X$. This process of updating the probabilities in the network is accomplished using Bayes' theorem:

$$
P\left(Y_{j=i} \mid X\right)=\frac{P\left(X \mid Y_{j=i}\right) P\left(Y_{j=i}\right)}{P(X)}
$$

The term on the left hand side of the equation is the posterior probability, the probability that variable $Y$, with $j=\{1,2, \ldots, i, \ldots n\}$ possible states, is in state $i$ given evidence about the distribution of parent nodes, $X . P\left(Y_{j=i}\right)$ is called the prior probability, the probability that $Y$ is in the $i^{\text {th }}$ state before the evidence became available. $P\left(X \mid Y_{j=i}\right)$ is the likelihood, which is the conditional probability of observing the evidence $(X)$ given that $Y$ is in the $j^{\text {th }}$ state. By the theorem of total probability, the denominator is 


$$
P(X)=\sum_{j=1}^{n} P\left(X \mid Y_{j}\right) P\left(Y_{j}\right)
$$

Additional information on updating of probabilities in Bayesian networks can be found in Kjaerulff and Madsen (2008), Koller and Friedman (2009), and Darwiche (2009). Koller and Friedman (2009) and Darwiche (2009) describe exact and approximate algorithms for performing these computations. While these algorithms are beyond the scope of this brief introduction, it should be noted that the ability to perform mathematically exact calculations of the probabilities efficiently is one of the primary advantages of Bayesian networks. As networks increase in size, the computational burden increases exponentially (Darwiche 2009). Networks containing several hundreds of nodes or thousands of nodes may need to be solved using approximate inference algorithms.

Figure 2 demonstrates predictive and diagnostic inference by instantiation. Figure 2(a) demonstrates instantiation of node X2 for predictive inference using the network presented in Figure 1. For example, node X2 is instantiated with hard evidence reflecting perfect information about its state. This affects the degree of belief that nodes $\mathrm{X}_{3}, \mathrm{X}_{4}$, and $\mathrm{X}_{5}$ are in each of their respective states. For example, comparing to Figure 1(b), knowledge that node $\mathrm{X}_{2}$ is in state $\mathrm{D}$ increases the probability that node $\mathrm{X}_{4}$ is in state $\mathrm{L}$ from 18 percent to 75 percent. Figure 2(b) demonstrates diagnostic inference. Perfect knowledge about the state of node $\mathrm{X}_{5}$ enables us to update beliefs about the state of other nodes in the network. For example, Figure 2(b) shows that if we know that node $\mathrm{X}_{5}$ is in state $\mathrm{S}$, the probability that node $\mathrm{X} 1$ is in state $\mathrm{C}$ increases from 20 percent to 48.3 percent and the probability that node $\mathrm{X}_{3}$ is in state $\mathrm{J}$ increases from 27.5 percent to 61 percent.

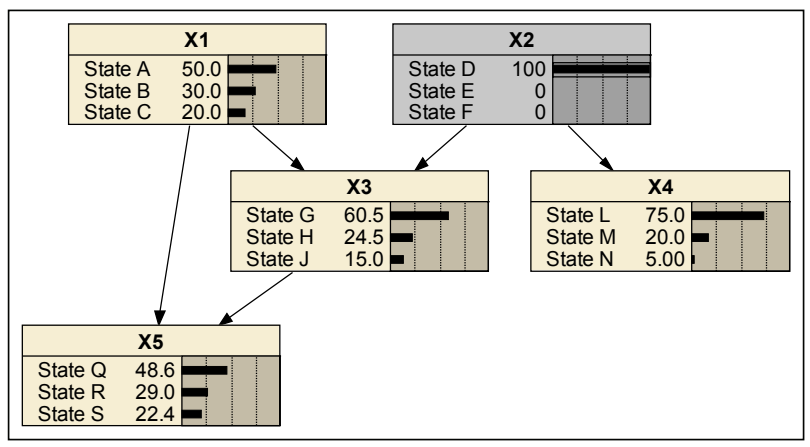

(a)

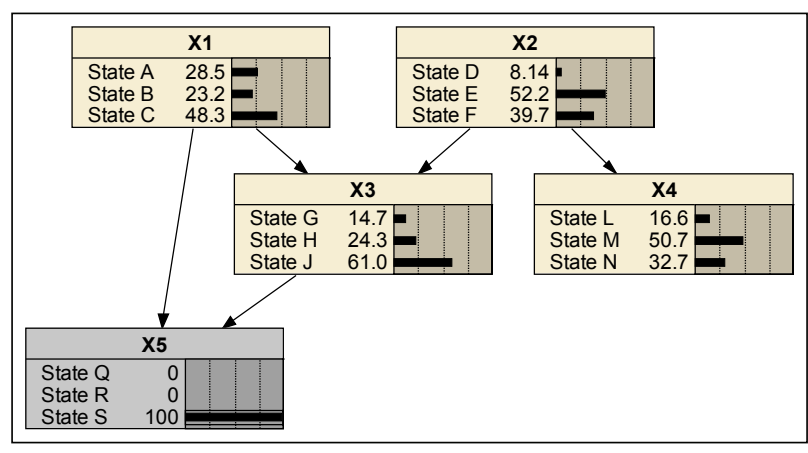

(b)

Figure 2. Instantiation of a Bayesian network. Instantiation of node X2 for predictive inference (a) and instantiation of node $X 5$ for diagnostic inference (b). 


\section{Construction of Bayesian Networks}

Bayesian networks are constructed by structuring the network and populating marginal probability tables, or CPTs. Two basic approaches to constructing Bayesian networks exist and many applications integrate the two (Darwiche 2009). The first, which is largely subjective, is called knowledge representation. Using this approach, the modeler uses his/her knowledge about cause and effect within the system or the knowledge of others to structure the graphical model and assess the probabilities. Alternatively, the modeler can synthesize some other type of formal knowledge, such as blueprints, flow charts, or diagrams. The second approach to constructing Bayesian networks is called machine learning or learning from data. In this approach, an artificial neural network is derived from data. Both the structure of a network and the probability tables can be learned from data using one of several available algorithms. A common integration of the two approaches involves networks that are structured using a knowledge representation approach and CPTs that are learned from data or model outputs.

\section{Network Structure}

Structuring the network involves first identifying the variables of interest. Each variable is represented by a node and its potential states are identified. Variables are then linked to indicate dependence and independence relationships among them. Using a knowledge representation approach, links are typically made by reasoning from causes to effects. A causal link between nodes means that a change in the parent node causes a change in the state of the child node. This approach helps to ensure proper representation of dependence and independence relationships (Darwiche 2009, Kjaerulff and Madsen 2008). While causal reasoning is often used to structure a network, the linkage between a parent node and a child node does not necessarily imply causality. ${ }^{1}$ However, links within a network often do indicate causality and it is usually best to work from information about

\footnotetext{
1 Directed edges between a parent node and a child node do not necessarily imply a causal relationship. For example, imagine a very simple network containing two nodes that represent traffic lights, one observable and the other unobservable. If we know that the two traffic lights turn green at about the same time, then the probability that the unobservable traffic light is green can be conditioned on the observable traffic light without implying that the observable traffic light causes the unobservable traffic light to turn green.
} 
causality when constructing a Bayesian network (Kjaerulff and Madsen 2008, Darwiche 2009, Marcot et al. 2006). A knowledge representation approach is the most common approach to structuring networks and input from experts and stakeholders is often sought to complete this task.

As an alternative to knowledge representation, a learning approach can also be used to obtain the structure of a network. However, this requires substantial amounts of data and it is rarely used in practical applications. Aside from the difficulty of obtaining a sufficient quantity of data, algorithms structure networks in ways that reflect the structure of whatever data happen to be available rather than a practical understanding of the system being modeled. The results of these algorithms may be difficult to interpret or may be nonsensical to subject matter experts. If diagnostic inference is an objective, networks developed using learning algorithms may be less than ideal because of spurious links between nodes or the absence of required links between nodes. In addition, Darwiche (2009) reports that Bayesian networks developed using the knowledge representation approach tend to be larger and more computationally demanding than those developed using a learning approach. Learning also offers an objective approach to network construction. However, learning requires a sufficient set of data to employ the algorithms and data are often sparse. In addition, low probability events may not be adequately represented in the database.

\section{Conditional Probability Tables (CPTs)}

CPTs can be developed through expert elicitation, data analysis, or postprocessing of model outputs. Elicitation of probabilities involves a series of in-depth interviews with those having intimate knowledge of a system. During the interviews, participants are asked questions similar to the following: "Given information about the state of node $X$ 's parents, what is the probability that variable $X$ takes state $i$ ?" (Pollino et al. 2007b). This series of questions continues until all possible combinations of system states are exhausted. Not surprisingly, developers of Bayesian networks often find that experts are sometimes reluctant to provide the necessary probabilities. When probabilities are obtained through expert elicitation, analysts should be aware that experts are not necessarily very good at estimating probabilities. Finally, all probabilities that are obtained from experts should be validated for coherence by ensuring that they conform to probability axioms. 
As an alternative to expert elicitation, some or all of the CPTs in a Bayesian network can be estimated from data. Generally, the approach is to construct a database of cases (called a case file). Each row in the database represents an observation of the system and each column represents a variable in the network. The elements of the data set are the state of each variable in that observation. An algorithm is then used to learn the probabilities from the cases. Common learning algorithms include the Lauritzen Spiegelhalter method, the expectation maximization (EM) method, and the gradient descent algorithm. Pollino et al. (2007b) provide a brief overview of these algorithms. Computationally, learning probabilities from data can be much less difficult than learning model structure. However, it can still be difficult to obtain sufficient quantities of data to learn conditional probabilities because rare combinations of system states are typically underrepresented in the case files. While there are no minimum sample sizes needed to learn probabilities, limits in the amount of data available can impose limits on the number of discrete levels used to represent a variable (Uusitalo 2007). This may limit the ability to represent complex joint probability distributions.

Bio-physical and engineering models can also be an important source of information for assessing conditional probabilities. When models are allowed to represent the system, simulation outputs generated through a systematic series of deterministic model runs or through Monte Carlo simulation can be used to construct a case file. The above-mentioned algorithms can then be employed to derive the conditional probabilities from model outputs. Conditional probabilities have typically been based on either data or engineering judgment, but rarely both. Pollino et al. (2007b) discuss ways of combining expert elicitation and data learning algorithms to populate CPTs for network nodes. Seoane et al. (2005) found that combining expert opinion with independent objective data improved the ability to predict the presence of bird species (Nyberg Marcot and Sulyma 2006).

\section{Best Practices for Constructing Bayesian Network Models}

Network structures should be developed using a causal reasoning approach in which parent nodes represent causes and child nodes represent effects (Koller and Friedman, 2009). Like all models, Bayesian networks are simplifications of real systems and the simplest possible network structure should be used (Barton et al. 2008). Simplification can be achieved by limiting the random variables in the network to those that can be observed or that the modeler may want to query (Koller and Friedman, 2009). Each 
node should have at least two parents or at least two children, although exceptions to this rule exist in the case of a mediating variable designed to transform one node for inference about a downstream node. The number of links between nodes should also be minimized by eliminating edges between nodes when the effect of one node on the other is thought to be small (Marcot et al. 2006). Marcot et al. (2006) also recommends limiting the number of parent nodes to three to minimize the complexity of CPTs. Large numbers of parent nodes can cause CPTs to become very large, particularly when the child node has a large number of discrete intervals. Large CPTs can become very difficult to populate. The number of undirected loops in the acyclic graph should also be minimized because computational requirements increase exponentially with the number of undirected loops. An undirected loop (not a directed cycle) occurs when there is a pathway leading from a parent through a child and back to the parent via an alternate route (which may go against the direction of the edges).

Best practices should also be considered with respect to the discretization of variable nodes. It is a requirement of the method that the set of possible states for each node be mutually exclusive and collectively exhaustive. If states of a node are mutually exclusive, this means that - given an observation of a random variable's state in nature - there is no ambiguity about which state should be coded in the network. This should not be a problem if nodes are "well-specified," meaning that the quantities represented by a node pass a clarity test: "Could a clairvoyant say unambiguously whether the event will or had occurred, or could he give the exact numerical value of the quantity" (Morgan and Henrion 1990, Howard and Matheson 1984). A collectively exhaustive set of states simply means that, for any possible state of the variable in nature, there is a corresponding node state. The level of resolution in each node is important because too few states can lead to errors in inference and too many states can lead to high levels of computational effort and complex CPTs. It is best to choose variable states that are meaningful in terms of the problem. For example, Marcot et al. (2006) suggests that, when modeling ecological systems, the modeler should use a minimum number of ecologically significant intervals, with the lower and upper bounds of each interval based on ecologically critical values of the variable. 


\section{Influence Diagrams}

Bayesian networks have been adapted for decision modeling. While a Bayesian network is designed for reasoning under uncertainty, an influence diagram is designed for reasoning about decision making under uncertainty (Kjaerulff and Madsen 2008). As with all valid decision models, there are a number of important normative assumptions that describe how decisions should be made. These axioms of rationality (ordering, transitivity, continuity, substitution, monotonicity, reduction of compound events, invariance, and finiteness) were developed by von Neumann and Morgenstern (1947) and are briefly summarized in Schultz et al. (2010). It is also assumed that there is a single rational decision maker. Schultz et al. (2010) discuss how decision models can be used to aide decisions involving multiple stakeholders through sensitivity analysis of the decision model.

In addition to the customary chance nodes of a Bayesian network, an influence diagram includes a decision node that identifies the decision alternatives under consideration and a utility or value node that describes the outcomes, which are expressed as some mathematical function of value node parents. Figure 3 shows an influence diagram consisting of five chance nodes, one decision node, and one utility node. Decision nodes and utility nodes in influence diagrams are fundamentally different from chance nodes that represent variables. Chance nodes are defined by marginal probability tables or CPTs. Decision nodes are defined by a list of alternatives. Utility nodes are defined by a table of outcome values conditional on the state of its parents. It is possible to include multiple decision nodes and multiple utility (or value) nodes in a single network.

In a conventional influence diagram, neither the decision node nor the value node is defined using probability tables. While there are some advantages to this approach, some authors prefer to represent decision nodes and value nodes as chance nodes. In practice, this can be more computationally efficient. In this approach, the decision node is represented by a chance node in which each alternative describes a potential state and each possible state is assigned equal probability of occurring. Likewise, the utility node is represented by a chance node and the probabilities of outcomes are derived from the utility (value) function and the probabilities of parent nodes. In influence diagrams structured using this approach, the utility node may be 
referred to as an outcome node and it is typical to have multiple outcome nodes in a single network. Influence diagrams differ from Bayesian networks in one other respect. When constructing influence diagrams, the links among nodes must represent both causality and probabilistic dependence (Kjaerulff and Madsen 2008).

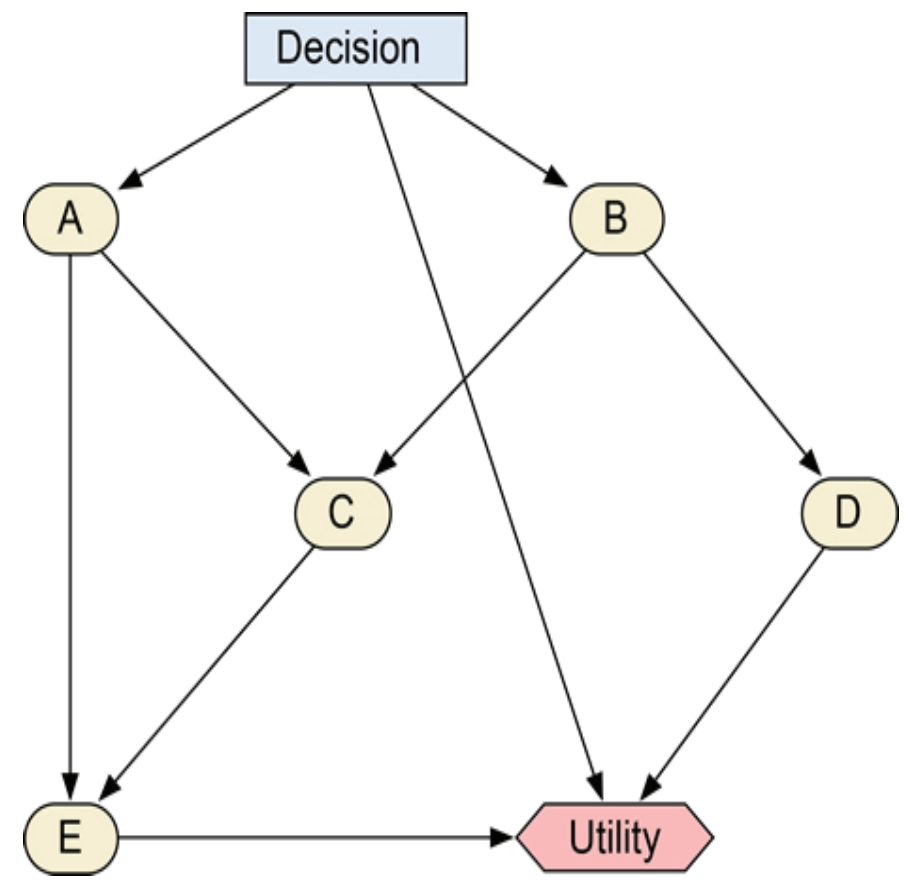

Figure 3. An influence diagram consisting of five chance nodes, one decision node, and one utility node. 


\section{Examples of Bayesian Networks in the Literature}

There have been many applications of Bayesian networks to diagnose causes of ecological problems and to predict the outcomes of environmental management decisions. Table 1 lists 32 examples of Bayesian networks applied to environmental inference and decision problems. For example, Pollino et al. (2007a) developed a Bayesian network to assess the probability of the potential causes leading to dieback of an endangered plant, Eucalyptus camphora, in the Yellingbo Nature Conservation Reserve, Victoria, Australia. Predictions were used to guide future management and research efforts and improve understanding of the causal factors leading to the species decline at different sites within the reserve. In another example, Kuikka et al. (1999) developed an influence diagram to consider whether or not a change in mesh size would benefit a Baltic cod fishery. The authors assess how environmentally driven uncertainties in recruitment and growth, including alternative models for recruitment, might affect cod management. For each entry, Table 1 indicates what substantive issue was addressed in each study, what type of environmental system was considered, and in general terms how the conditional probabilities were obtained. Where possible, Table 1 also notes what software was used to develop the network. This is by no means an exhaustive list of Bayesian network applications, but it is representative of recent work in this area. 
Table 1. Bayesian network applications reviewed in the literature.

\begin{tabular}{|c|c|c|c|c|c|}
\hline Author(s) & Year & Substantive issue addressed in the study & System type & $\begin{array}{l}\text { Conditional } \\
\text { probabilities }\end{array}$ & Software \\
\hline $\begin{array}{l}\text { Adriaenssens } \\
\text { et al. }\end{array}$ & 2004 & $\begin{array}{l}\text { Predict the presence and abundance of macro- } \\
\text { invertebrate taxa (Gammaridae and Asellidae) in } \\
\text { European rivers as a function of stream width, } \\
\text { velocity, dissolved oxygen, and conductivity. }\end{array}$ & $\begin{array}{l}\text { Rivers and } \\
\text { streams }\end{array}$ & $\begin{array}{l}\text { Learning from } \\
\text { data }\end{array}$ & Netica \\
\hline Ames et al. & 2005 & $\begin{array}{l}\text { Evaluate watershed management alternatives by } \\
\text { estimating the probability of meeting water } \\
\text { quality criteria for phosphorous concentrations in } \\
\text { the East Canyon watershed of Utah. }\end{array}$ & Watersheds & $\begin{array}{l}\text { Model } \\
\text { simulation, } \\
\text { literature, } \\
\text { experts }\end{array}$ & - \\
\hline Amstrup et al. & 2008 & $\begin{array}{l}\text { Assess the probability of polar bear (Ursus } \\
\text { maritimus) extinction in out years given } \\
\text { projections of habitat conditions under climate } \\
\text { change scenarios. }\end{array}$ & Arctic & Expert elicitation & Netica \\
\hline Bacon et al. & 2002 & $\begin{array}{l}\text { Identify factors that might lead to a change in } \\
\text { land use from farming to forestry in marginal } \\
\text { upland areas of the United Kingdom. }\end{array}$ & $\begin{array}{l}\text { Forests and } \\
\text { agricultural } \\
\text { lands }\end{array}$ & Elicitation & Netica \\
\hline Barton et al. & 2008 & $\begin{array}{l}\text { Evaluate eutrophication mitigation costs relative } \\
\text { to benefits in the Morsa river watershed of South } \\
\text { Eastern Norway. }\end{array}$ & Watersheds & $\begin{array}{l}\text { Model simulation } \\
\text { \& other sources }\end{array}$ & Hugin \\
\hline Borsuk & 2004 & $\begin{array}{l}\text { Assess the causes of the Atlantic menhaden } \\
\text { (Brevoortia tyrannus) fish kills in the Neuse River } \\
\text { estuary in North Carolina. }\end{array}$ & $\begin{array}{l}\text { Oceans and } \\
\text { estuaries }\end{array}$ & Expert elicitation & - \\
\hline Borsuk et al. & 2004 & $\begin{array}{l}\text { Evaluate non-point source management } \\
\text { strategies for preventing eutrophication in the } \\
\text { Neuse River Estuary, North Carolina. }\end{array}$ & $\begin{array}{l}\text { Oceans and } \\
\text { Estuaries }\end{array}$ & $\begin{array}{l}\text { Process-based } \\
\text { models and } \\
\text { expert elicitation }\end{array}$ & Analytica \\
\hline Borsuk et al. & 2006 & $\begin{array}{l}\text { Identify the reasons for decline of brown trout } \\
\text { (Salmo trutta) populations in Swiss rivers. }\end{array}$ & $\begin{array}{l}\text { Rivers and } \\
\text { streams }\end{array}$ & $\begin{array}{l}\text { Multiple } \\
\text { methods }\end{array}$ & Analytica \\
\hline Borsuk et al. & 2011 & $\begin{array}{l}\text { Predict the morphological, hydraulic, economic, } \\
\text { and ecological consequences of river } \\
\text { rehabilitation activities. }\end{array}$ & $\begin{array}{l}\text { Rivers and } \\
\text { streams }\end{array}$ & Model simulation & Analytica \\
\hline Bromley et al. & 2005 & $\begin{array}{l}\text { Select demand-side water management } \\
\text { strategies. }\end{array}$ & $\begin{array}{l}\text { Municipal } \\
\text { water systems }\end{array}$ & - & - \\
\hline $\begin{array}{l}\text { Burgman et } \\
\text { al. }\end{array}$ & 2010 & $\begin{array}{l}\text { Assess the probability of locating and } \\
\text { successfully eradicating red imported fire ants } \\
\text { (Solenopsis invicta) in southern Queensland, } \\
\text { Australia using various treatment alternatives. }\end{array}$ & $\begin{array}{l}\text { Invasive } \\
\text { species }\end{array}$ & Expert elicitation & Netica \\
\hline Gibbs & 2007 & $\begin{array}{l}\text { Evaluate the risks posed by aquaculture } \\
\text { development to shorebird populations in New } \\
\text { Zealand. }\end{array}$ & $\begin{array}{l}\text { Oceans and } \\
\text { estuaries }\end{array}$ & See paper & - \\
\hline Kragt et al. & 2009 & $\begin{array}{l}\text { Evaluate watershed management alternatives in } \\
\text { the George watershed on the northeast coast of } \\
\text { Tasmania using a Bayesian network that } \\
\text { integrates biophysical and economic models. }\end{array}$ & Watersheds & $\begin{array}{l}\text { Model simulation } \\
\text { and data from } \\
\text { elicitation }\end{array}$ & - \\
\hline Kuikka et al. & 1999 & $\begin{array}{l}\text { Determine the best mesh size for use in the } \\
\text { Baltic cod (Gadus morhua) fishery and how } \\
\text { uncertainties in recruitment and growth might } \\
\text { affect cod management decisions. }\end{array}$ & $\begin{array}{l}\text { Oceans and } \\
\text { estuaries }\end{array}$ & Model simulation & - \\
\hline Lee et al. & 1997 & $\begin{array}{l}\text { Assess the risks of land use decisions to } \\
\text { salmonid populations in the Pacific Northwest. }\end{array}$ & $\begin{array}{l}\text { Rivers and } \\
\text { streams }\end{array}$ & Model simulation & - \\
\hline
\end{tabular}




\begin{tabular}{|c|c|c|c|c|c|}
\hline Marcot & $2006 a$ & $\begin{array}{l}\text { Predict the presence of a species in a plot of } \\
\text { land area. }\end{array}$ & $\begin{array}{l}\text { Forests and } \\
\text { agricultural } \\
\text { lands }\end{array}$ & Expert elicitation & Netica \\
\hline Marcot & $2006 b$ & $\begin{array}{l}\text { Determine whether to conduct surveys on the } \\
\text { ground to determine the presence of a particular } \\
\text { sensitive species at a location. }\end{array}$ & $\begin{array}{l}\text { Forests and } \\
\text { agricultural } \\
\text { lands }\end{array}$ & Expert elicitation & Netica \\
\hline McNay et al. & 2006 & $\begin{array}{l}\text { Classify habitat suitability and evaluate the } \\
\text { efficacy of woodland caribou (Rangifer tarandus) } \\
\text { habitat management alternatives. }\end{array}$ & $\begin{array}{l}\text { Forests and } \\
\text { agricultural } \\
\text { lands }\end{array}$ & Expert elicitation & Netica \\
\hline $\begin{array}{l}\text { Newman et } \\
\text { al. }\end{array}$ & 2007 & $\begin{array}{l}\text { Identify the most likely causes of liver lesions in } \\
\text { fish populations of Puget Sound, Washington. }\end{array}$ & $\begin{array}{l}\text { Oceans and } \\
\text { estuaries }\end{array}$ & $\begin{array}{l}\text { Graphical } \\
\text { structure only }\end{array}$ & - \\
\hline Nyberg et al. & 2006 & $\begin{array}{l}\text { Assess the suitability of forest stands to provide } \\
\text { woodland caribou (Rangifer tarandus) winter } \\
\text { forage employing active adaptive management } \\
\text { techniques. }\end{array}$ & $\begin{array}{l}\text { Oceans and } \\
\text { estuaries }\end{array}$ & $\begin{array}{l}\text { Expert elicitation } \\
\text { and literature } \\
\text { sources }\end{array}$ & Netica \\
\hline $\begin{array}{l}\text { Petersen et } \\
\text { al. }\end{array}$ & 2008 & $\begin{array}{l}\text { Evaluate trade-offs in the decision to remove } \\
\text { barriers to fish migration in mountain streams } \\
\text { considering the potential for population threats } \\
\text { to isolated westslope cutthroat trout } \\
\text { (Oncorhynchus clarki lewisi) and invasion of non- } \\
\text { native fish species. }\end{array}$ & $\begin{array}{l}\text { Rivers and } \\
\text { streams }\end{array}$ & $\begin{array}{l}\text { Multiple } \\
\text { methods }\end{array}$ & Netica \\
\hline Pike & 2004 & $\begin{array}{l}\text { Assess the probability of drinking water } \\
\text { treatment plant violations using information } \\
\text { about conditions inside and outside the plant. }\end{array}$ & $\begin{array}{l}\text { Municipal } \\
\text { water systems }\end{array}$ & $\begin{array}{l}\text { Engineering } \\
\text { judgment and } \\
\text { data }\end{array}$ & - \\
\hline Pollino et al. & $2007 a$ & $\begin{array}{l}\text { Identify the causes leading to dieback of an } \\
\text { endangered plant species (Eucalypt camphora). }\end{array}$ & $\begin{array}{l}\text { Plant } \\
\text { communities }\end{array}$ & $\begin{array}{l}\text { Learning from } \\
\text { data }\end{array}$ & Netica \\
\hline Pollino et al. & 2007b & $\begin{array}{l}\text { Evaluate the impact of changes in hydraulic and } \\
\text { structural habitat on future fish abundance and } \\
\text { future fish diversity in the Goulburn River, } \\
\text { Victoria, Australia. }\end{array}$ & $\begin{array}{l}\text { Rivers and } \\
\text { streams }\end{array}$ & $\begin{array}{l}\text { Expert elicitation } \\
\text { and learning } \\
\text { from data }\end{array}$ & Netica \\
\hline $\begin{array}{l}\text { Sadoddin et } \\
\text { al. }\end{array}$ & 2005 & $\begin{array}{l}\text { Evaluate the influence of dryland salinity } \\
\text { management alternatives on physical, social, } \\
\text { ecological, and economic outcomes in the } \\
\text { Goulburn watershed, Australia. }\end{array}$ & Watersheds & - & - \\
\hline Shepard et al. & 1997 & $\begin{array}{l}\text { Assess the causes behind westslope cutthroat } \\
\text { trout population declines in western Montana. }\end{array}$ & $\begin{array}{l}\text { Rivers and } \\
\text { streams }\end{array}$ & Model simulation & - \\
\hline Smith et al. & 2007 & $\begin{array}{l}\text { Assess the suitability of habitat for the Julia } \\
\text { Creek dunnart (Sminthopsis douglasi), an } \\
\text { endangered marsupial. }\end{array}$ & Grasslands & - & Netica \\
\hline $\begin{array}{l}\text { Stewart- } \\
\text { Koster et al. }\end{array}$ & 2010 & $\begin{array}{l}\text { Identify the best strategies for managing } \\
\text { dissolved oxygen in streams. }\end{array}$ & $\begin{array}{l}\text { Rivers and } \\
\text { streams }\end{array}$ & Expert elicitation & Netica \\
\hline $\begin{array}{l}\text { Stewart- } \\
\text { Koster et al. }\end{array}$ & 2010 & $\begin{array}{l}\text { Identify the best strategies for managing invasive } \\
\text { aquatic nuisance macrophytes in streams. }\end{array}$ & $\begin{array}{l}\text { Rivers and } \\
\text { streams }\end{array}$ & $\begin{array}{l}\text { Learning from } \\
\text { data }\end{array}$ & Netica \\
\hline $\begin{array}{l}\text { Ticehurst et } \\
\text { al. }\end{array}$ & 2007 & $\begin{array}{l}\text { Assess the sustainability of social, economic, } \\
\text { and environmental values in coastal lake } \\
\text { catchments in New South Wales, Australia. }\end{array}$ & Watersheds & $\begin{array}{l}\text { Multiple } \\
\text { methods }\end{array}$ & ICMS \\
\hline $\begin{array}{l}\text { Ticehurst et } \\
\text { al. }\end{array}$ & 2008 & $\begin{array}{l}\text { Evaluate management alternatives for } \\
\text { Merimbula Lake in New South Wales considering } \\
\text { economic, social, and environmental factors. }\end{array}$ & Lakes & - & ICMS \\
\hline
\end{tabular}




\section{Dredging Decision Models}

Information about the potential environmental impacts of dredging operations is a critical factor that must be considered when planning, designing, constructing, and maintaining navigation systems. While, in general, the potential environmental impacts of dredging operations are well known (e.g., see Table 2), there is a great deal of uncertainty associated with predicting the environmental outcomes of any particular navigation or dredging project. In addition, aquatic systems are highly complex systems and there is limited information regarding the physical, chemical, and biological processes governing each system. Bayesian networks are an approach to structuring information about uncertainty in an efficient way so that it may be accounted for in the decision making process. In addition, the opportunity exists to adapt Bayesian networks developed for dredging decisions to perform diagnostic reasoning that can be used to address broader management questions about the system.

The Bayesian network approach enables the developer to integrate the results of multiple bio-physical and engineering models that address more narrow aspects of the system to create a comprehensive systems-level model. This can be accomplished even if each of these models is considered incompatible with the others because of issues related to, for example, spatial and temporal scale or the difficulty of transferring outputs from one model to another. Bayesian networks also permit information to be expressed in both qualitative and quantitative terms while preserving mathematical rigor in the analysis of uncertainty. For example, changes in benthic habitat suitability may be expressed best in terms of an increase or decrease rather than in terms of a quantitative measure of habitat quality. Similarly, objective and subjective knowledge can also be integrated. If engineering judgment is used in the course of the decision making process, uncertainty about this knowledge can be evaluated and accounted for in the decision model.

The advantage of using graphical models as tools for interacting with stakeholders and incorporating information about their concerns into the decision making process has been widely discussed in the literature (e.g., McCann et al. 2006). Incorporating these concerns is a key to under 
Table 2. A summary of the potential environmental impacts of dredging operations (Newcombe and McDonald 1991, Newcombe and Jensen 1996, Reine et al. 1998, Herbich 2000, Wilber and Clarke 2001, Bray 2008, Suedel et al. 2008, PIANC 2009).

\begin{tabular}{|c|c|}
\hline Impact & Description of impact \\
\hline Change in salinity & $\begin{array}{l}\text { Deepening of coastal inlets may alter the tidal prism and may tend to increase the } \\
\text { salinity of brackish water in bays and estuaries, potentially altering the character of } \\
\text { the biotic community. }\end{array}$ \\
\hline Change in currents & $\begin{array}{l}\text { Changes in bathymetry lead to changes in the direction and velocity of currents, } \\
\text { altering patterns of shoreline erosion and accretion and leading to instability in the } \\
\text { location of the shoreline. }\end{array}$ \\
\hline $\begin{array}{l}\text { Change in wave } \\
\text { climate }\end{array}$ & $\begin{array}{l}\text { Deepening of coastal waters can lead to changes in wave climate. Deeper waters } \\
\text { tend to support higher waves and to permit storm tides to penetrate deeper inland. }\end{array}$ \\
\hline $\begin{array}{l}\text { Modification of } \\
\text { habitat }\end{array}$ & $\begin{array}{l}\text { The benthic surface that is altered by dredging may lack the topographic diversity of } \\
\text { the former surface and the depth may increase; either condition may lead to changes } \\
\text { in the character of the biotic community populating the benthic surface. }\end{array}$ \\
\hline $\begin{array}{l}\text { Removal of aquatic } \\
\text { organisms }\end{array}$ & $\begin{array}{l}\text { Fish, shellfish, and sea turtles can become entrained with sediment and removed } \\
\text { from the site. Fast-moving, surface-dwelling species tend to re-colonize disturbed } \\
\text { habitats more easily than sessile organisms. }\end{array}$ \\
\hline $\begin{array}{l}\text { Resuspension of } \\
\text { sediments }\end{array}$ & $\begin{array}{l}\text { Increases in turbidity and suspended solids concentration can reduce primary } \\
\text { productivity, clog filter feeders, abrade fish gill tissues and smother egg masses. } \\
\text { Behavioral and physiological effects include abandonment of cover, departure from } \\
\text { migratory pathways, reduced growth and reproductive rates and increased mortality. }\end{array}$ \\
\hline $\begin{array}{l}\text { Release of nutrients } \\
\text { and organic mater }\end{array}$ & $\begin{array}{l}\text { Increased nutrient and organic matter concentrations in the water column can } \\
\text { reduce dissolved oxygen concentrations and lead to eutrophication. }\end{array}$ \\
\hline $\begin{array}{l}\text { Release and } \\
\text { redistribution of } \\
\text { contaminants }\end{array}$ & $\begin{array}{l}\text { Contaminants attached to sediment may be released into the water column and } \\
\text { accumulate in plants, fish, shellfish and predatory species that feed on aquatic } \\
\text { organisms. Potential effects include physiological impairment (fish liver lesions, etc.), } \\
\text { mortality, and fishery closures. }\end{array}$ \\
\hline Disturbance & $\begin{array}{l}\text { Dredgers cause air pollution, noise pollution, and vibration at the dredging site. Rock } \\
\text { blasting during capital dredging projects can cause shock waves. Disturbance may } \\
\text { interfere with marine mammals. }\end{array}$ \\
\hline $\begin{array}{l}\text { Smothering of } \\
\text { organisms }\end{array}$ & $\begin{array}{l}\text { Smothering of organisms: The placement of dredged material can smother benthic } \\
\text { fauna and plants that are located in the designated placement area. }\end{array}$ \\
\hline
\end{tabular}

standing whether or not divergent beliefs held by different stakeholders might lead to the implementation of different alternatives. If not, those concerns can be set aside and conflict among stakeholders can be avoided. Bayesian networks also provide a platform for adaptive management, a process by which decisions are re-evaluated after collecting new information, and value of information (VOI) analysis, a type of analysis to estimate the benefits of reducing uncertainty in specific variables and prioritize data collection needs.

The purpose of a dredging decision model is to identify the alternative that maximizes the expected net benefit of a decision within the context of the 
objectives and value system defined by the decision maker. Decision models can be developed for any type of dredging decision. Examples of the types of dredging decisions that might be modeled include:

- Should a navigation channel be authorized or constructed (or deepened)?

- Which potential location is the best location for the navigation channel?

- Should a more detailed environmental assessment be completed?

- What are the best dimensions for the navigation channel?

- Should the navigation channel be dredged to authorized depth, and if not - how deep should the navigation channel be dredged?

- What type of dredging equipment should be used? Which type is most cost-effective?

- What is the best environmental window for dredging operations?

- What operating limits should be placed on dredgers (e.g., operating speed, bucket size, etc.)?

- What dredged material disposal alternative maximizes the net benefits of a dredging project?

- How frequently should a navigation channel be scheduled for dredge maintenance?

- Which sediment disposal alternative should be selected? 


\section{The Port Essayons Dredging Decision Problem}

The example provided here is based on a case study developed for a hypothetical estuary. The purpose of this example is to illustrate how a decision model might be developed, structured, and parameterized for a dredging decision problem using a Bayesian network approach. Several USACE bio-physical and engineering models have been integrated into the decision model and a subset of the decision model is used to demonstrate statistical inference and VOI analysis.

The Port Essayons navigation channel is located in an estuary that extends over a $4 \times 5 \mathrm{~km}\left(5 . \mathrm{OE}_{7} \mathrm{~m}^{2}\right)$ area and has an average depth of 4 meters. A one $\mathrm{km}$ by 100 meter section of the navigation channel has been scheduled for maintenance dredging to remove $0.5 \mathrm{~m}$ of sediment that has accumulated through siltation. The port authority must select a sediment removal and disposal alternative for the sediment, which is laden with polychlorinated biphenyls (PCBs) that originate in runoff from legacy industrial sites. The sediment in runoff preferentially settles in the navigation channel. Measured PCB concentrations ranged from o to $0.5 \mathrm{mg} / \mathrm{kg}$. The release of suspended solids and associated PCBs into the water column has the potential to cause damage to the local sea bass (Centropristis $s p$.) fishery. Contaminated sediment must be disposed of either by placement in a confined disposal facility (CDF) or in a confined aquatic disposal (CAD) pit. The decision maker identifies four alternatives, including:

1. No dredging (No_Dredging)

2. Bucket dredging with disposal in a CDF (Bucket_CDF)

3. Bucket dredging with disposal in a CAD pit (Bucket_CAD)

4. Cutterhead dredging with pipeline placement in the $\mathrm{CDF}$ (Cutterhead_CDF)

Placement of cutterhead dredged material in the CAD pit is not considered a feasible alternative because of limited CAD pit volume. Hydraulically dredged material has a lower bulk density because of high water content and requires a greater volume of available capacity for placement than mechanically dredged sediment. 
The port authority's objective is to maximize expected net benefits of the dredging project. The project will reduce shipping costs, but these benefits may be offset by costs to the fishing industry. Dredging will increase total suspended solids (TSS) concentrations in the water column and redistribute PCBs to areas outside the channel, leading to a potential increase in the fish tissue PCB concentrations. Potential damage to the fishery from exposure to high concentrations of TSS is estimated using the method of Newcombe and MacDonald (1991), which estimates the severity of suspended sediment effects on fish as a function of the dose of total suspended sediment (TSS). PCB concentrations in fish tissue were estimated as a function of sediment concentrations using a biota-sediment accumulation factor (BSAF) from the USACE BSAF Database (http://el.erdc.usace.army.mil/bsafnew/BSAF.html). If fish tissue PCB concentrations exceed a critical limit of $0.2 \mathrm{mg} / \mathrm{kg}$, the fishery will be closed until fish tissue concentrations return to an acceptable level (USEPA 2000).

The geometry of the estuary is illustrated in Figure 4. The estuary is segmented into four zones for the purpose of analysis: A no-impact zone where TSS and PCB concentrations will not be affected by dredging and three mixing zones where TSS and PCB concentrations will potentially be affected by dredging activity. The dimensions of the mixing zones correspond to the estimated anticipated maximum size of plumes caused by dredging and disposal. The impact zones do not overlap.

\section{The Port Essayons Decision Model}

A decision model for the Port Essayons dredging decision has been developed using a Bayesian network approach. The graphical model is shown in Figure 5. This Bayesian network has been developed using software called Netica, developed by Norsys Inc, Vancouver BC. The graph consists of 42 nodes, 82 edges, and 782,250 conditional probabilities. Each node in Figure 5 has been color-coded to indicate how it is classified in terms of five possible node types: decision node, site characteristic node ( $\mathrm{SCN}$ ), state-defining node (SDN), effect node (EFN), or value node. The five types of nodes can be described as follows: 


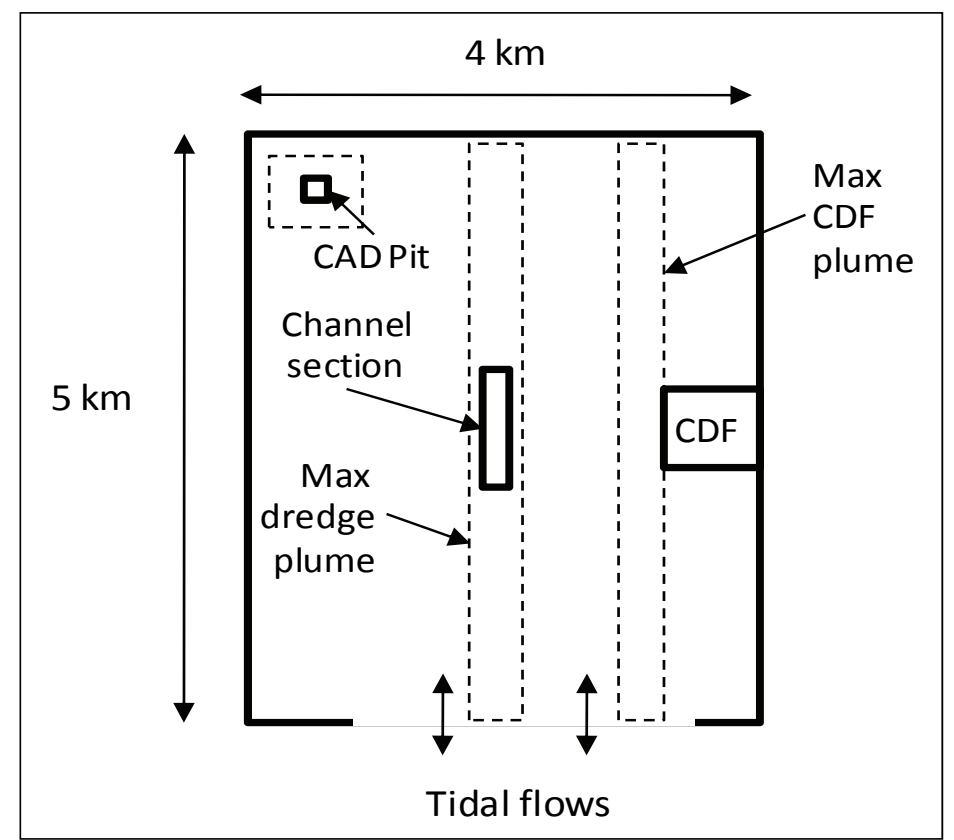

Figure 4. Port Essayons estuary. The figure shows the location of the navigation channel section to be dredged, the CAD pit, the $\mathrm{CDF}$, and the mixing zones. Dashed lines denote the boundaries of the mixing zones for the CAD pit, CDF, and dredge plume. Bidirectional arrows indicate the direction of tidal flow paths in an out of the estuary (Note: Figure not to scale).

- The decision node identifies four dredging and dredged material disposal alternatives (Bucket_CDF, Bucket_CAD, Cutterhead_CDF, and No_Dredging). This model includes one decision node. The decision node is parameterized by listing the alternatives under consideration. No probabilities are specified in the decision node. The decision node is color-coded blue.

- SCNs describe the physical, chemical, and biological conditions in the project area that will not be influenced by the decision maker's choice of alternative, but that will influence one or more of the effects that dredging may have in the estuary. These nodes have no parents. This decision model includes eleven SCNs. Uncertainty in SCNs can be described using data from the dredging site. SCNs are parameterized using a marginal probability table that specifies the probability that each possible state of the random variable accurately describes field conditions in the estuary. SCNs are color-coded orange. 


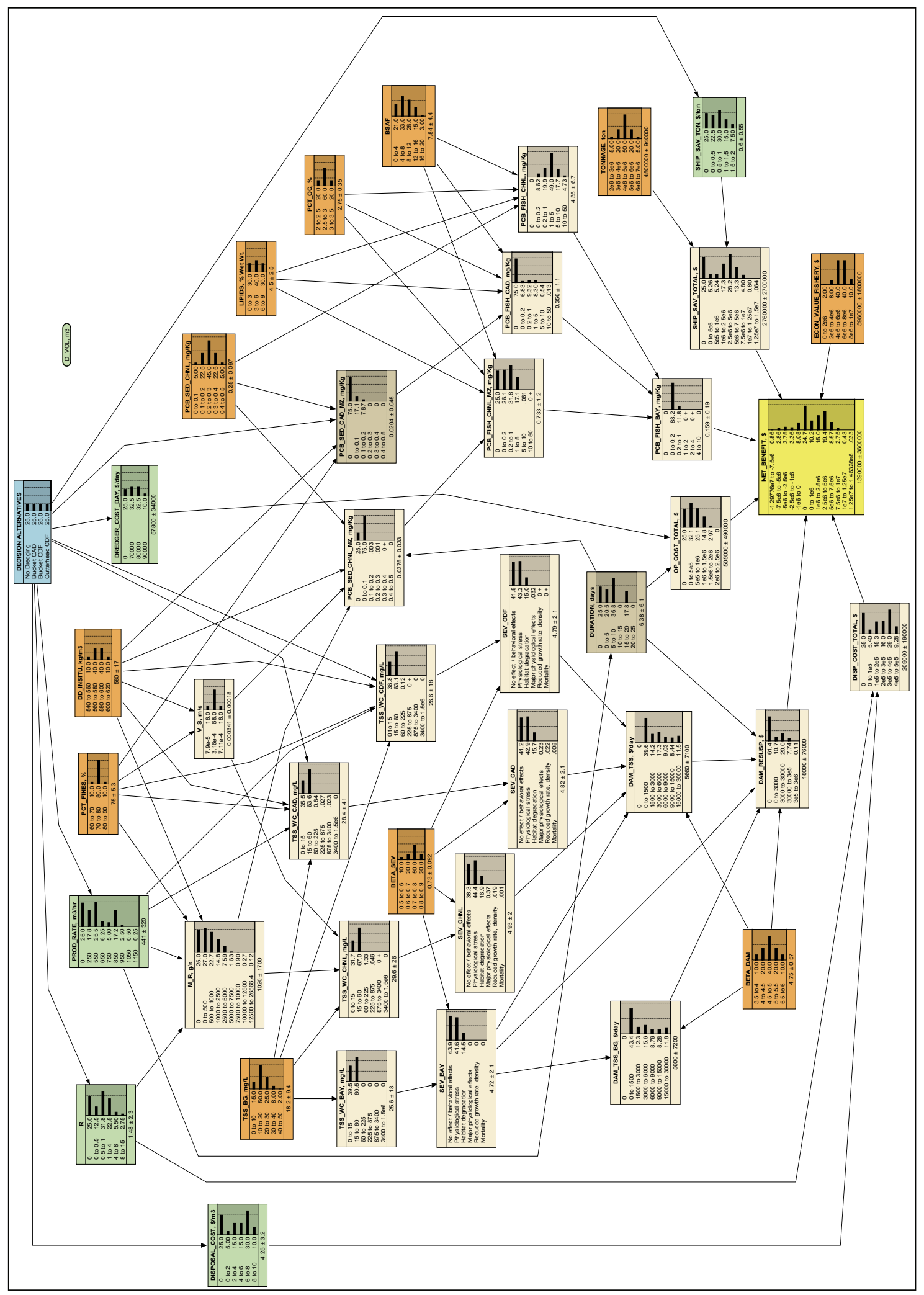

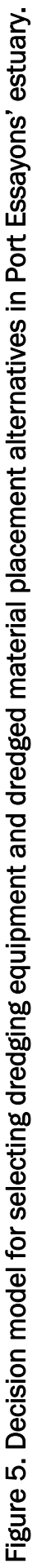


- SDNs describe the direct effect of each dredging and dredged material disposal alternative on a variable that will somehow influence conditions in the estuary. Although it is not the case in this network, SDNs may also be influenced by SCNs and EFNs. This decision model includes six SDNs. Five SDNs are random variables. One SDN, D_VOL, is a constant that represents the volume of material to be dredged. No edge is present that links this node with the decision node because it is not influenced by the choice of dredging and dredged material disposal alternative. Uncertainty in SDNs may be characterized using engineering judgment or using data from previous dredging efforts or pilot studies in the estuary. SDNs are color-coded green.

- EFNs are intermediate nodes in the network that describe conditions in the estuary that may or may not be directly observable. These nodes may be included in a Bayesian network because they are somehow transformative, permit proper modeling of the system or because the modeler may wish to study these conditions in subsequent analysis. EFNs may be influenced by SDNs, SCNs, and/or other EFNs. This decision model includes 22 EFNs. Uncertainty in EFNs may be characterized using data from the study site, by an equation, or by post-processing the results of bio-physical and engineering models. EFNs are parameterized using CPTs that specify the probability of observing a state for every possible combination of parent node states. EFNs are color-coded tan.

- The value node is the terminal node in the network that describes uncertainty in the net benefit of each alternative. In this decision model, net benefits are expressed in terms of a monetary value. All decision models include exactly one value node; however, Bayesian networks may contain more than one terminal node. The outcome node is color-coded yellow.

Definitions and descriptions of SCNs, SDNs, and selected EFNs are provided in Table 3 along with a brief explanation of the basis for each set of node states and their probabilities. Due to the fact that the purpose of this example is to demonstrate how a Bayesian network might be developed for a hypothetical dredging site, many of the variable ranges and state probabilities for SCNs and SDNs that would otherwise be based on site-specific data have been assumed for the purpose of this example. Where such assumptions have been made, variable ranges and their probabilities have been chosen to represent conditions that are regarded as typical for estuaries and dredging projects in the United States. The 
EFNs described in Table 3 have been parameterized using the outputs of USACE models developed for simulating the effects of dredging and dredged material disposal. The CPTs for these nodes are generated externally (using models) by post-processing the outputs of DREDGE, STFATE, and SETTLE and then imported into Netica. The remaining EFNs were parameterized using equations that were specified in the network. CPTs for these nodes are generated internally by Netica, which populates the CPT by sampling from parent nodes. In developing this example, 2,500 samples are obtained for each node. The following sections explain how EFNs were parameterized.

\section{TSS Concentrations}

TSS concentrations in dredge plumes and disposal-area mixing zones were modeled for each alternative for all possible states of parent nodes. The range of potential water column TSS concentrations is discretized to six possible states. Lower and upper limits of each concentration interval correspond to the critical concentrations for estimating the impacts of a TSS dose on migratory fish. A six-hour duration of exposure was assumed when calculating the dose to account for the influence of tides. CPTs are populated by calculating the fraction of grid cells within the boundaries of the mixing zone or plume areas that have concentrations within the limits of each possible state given the states of parent nodes.

TSS Concentrations in the Channel Mixing Zone (TSS_WC_CHNL)

Dredging activity will tend to increase TSS concentrations in the navigation channel and disposal area mixing zones. The sediment concentrations in the navigation channel vary with $M \_R$. M_R is calculated using the method of Hayes et al. (2007) and is a function of PROD_RATE, R, DD_INSITU, and PCT_FINES:

$$
M \_R=\frac{1}{3.6}\left(P R O D \_R A T E \cdot \frac{R}{100} \cdot D D \_I N S I T U \cdot \frac{P C T \_F I N E S}{100}\right)
$$


Table 3. SDN, SCN and EFN that were parameterized using data, model outputs, or engineering judgment. Nodes parameterized using equations are described in the text.

\begin{tabular}{|c|c|c|c|}
\hline Type & Symbol & Units & Description \\
\hline \multirow{11}{*}{ SCN } & DD_INSITU & $\mathrm{kg} / \mathrm{m}^{3}$ & $\begin{array}{l}\text { In-situ dry bulk density: The dry bulk density of sediment in the navigation channel. } \\
\text { DD_INSITU ranges from } 540 \text { to } 620 \mathrm{~kg} / \mathrm{m}^{3} \text { and is discretized into four possible states. } \\
\text { The marginal probabilities are assumed for the purpose of this example, but reflect the } \\
\text { frequency with which those values might be encountered in estuarine maintenance } \\
\text { dredging projects. }\end{array}$ \\
\hline & PCT_FINES & - & $\begin{array}{l}\text { Percent fines: The percent of sediment particles that are less than } 74 \text { microns in } \\
\text { diameter. PCT_FINES ranges from } 60 \text { to } 90 \text { percent and is discretized to three possible } \\
\text { states. The marginal probabilities for each state are assumed for the purpose of this } \\
\text { example, but reflect the frequency that these fractions might be encountered in } \\
\text { estuarine maintenance dredging projects. }\end{array}$ \\
\hline & TSS_BG & $\mathrm{mg} / \mathrm{L}$ & $\begin{array}{l}\text { Background total suspended sediment concentration in the channel: TSS_BG ranges } \\
\text { from } 0 \text { to } 50 \mathrm{mg} / \mathrm{L} \text { and is discretized to five possible states. The marginal probabilities } \\
\text { for each state are assumed for the purpose of this example, but in site-specific } \\
\text { applications could be based on monitoring data. }\end{array}$ \\
\hline & PCB_SED_CHNL & $\mathrm{mg} / \mathrm{kg}$ & $\begin{array}{l}\text { Concentration of PCBs in channel sediment: For the purpose of this example, it is } \\
\text { assumed that PCB-laden sediment in runoff tends to accumulate in the navigation } \\
\text { channel. PCB_SED_CHNL ranges from } 0 \text { to } 0.5 \mathrm{mg} / \mathrm{kg} \text { and is discretized to five } \\
\text { possible states. The range of PCB concentrations in sediment is similar to the range } \\
\text { that might be found in maintenance dredging projects of the type described in this } \\
\text { example. The marginal probabilities are assumed for the purpose of this example. }\end{array}$ \\
\hline & LIPIDS & - & $\begin{array}{l}\text { Percent lipids: Percent of fish tissue that is lipids. LIPIDS ranges from } 0 \text { to } 9 \text { percent wet } \\
\text { weight and is discretized to three states. Uncertainty in LIPIDS arises from natural } \\
\text { variability. Values and marginal probabilities are based on Kwon et al. (2007). }\end{array}$ \\
\hline & PCT_OC & - & $\begin{array}{l}\text { Percent organic carbon: Percent organic carbon in sediment. PCT_OC ranges from } 2 \text { to } \\
3.5 \text { percent and is discretized to three possible states. Uncertainty arises from natural } \\
\text { variability. Values and marginal probabilities are based on the USACE Dredged Material } \\
\text { Physical Properties Database (USACE In Prep). }\end{array}$ \\
\hline & BSAF & - & $\begin{array}{l}\text { Biota sediment accumulation factor for PCBs: BSAF ranges from } 0 \text { to } 20 \text { and is } \\
\text { discretized to five states. This range of values is based on MacDonald et al. (1993) for } \\
\text { adult smallmouth bass (Micropterus dolomieu). The mean BSAF is } 7.871 \text { and the } \\
\text { standard error is } 4.183 \text {. Uncertainty in BSAF is modeled using a beta distribution with } \\
\text { parameters } 1.75 \text { and 2.7. }\end{array}$ \\
\hline & TONNAGE & tons & $\begin{array}{l}\text { Cargo tonnage: The weight of cargo transported through the navigation channel. } \\
\text { TONNAGE ranges from 2E6 to } 7 \mathrm{E} 6 \text { tons and is discretized to five states. The values for } \\
\text { TONNAGE used in this example are assumed for the purpose of the example, but these } \\
\text { values are characteristic of small to medium sized port channels. }\end{array}$ \\
\hline & BETA_SEV & - & $\begin{array}{l}\text { Severity function parameter: Parameter of the function used to estimate the biological } \\
\text { response of fish to total suspended sediment dose. BETA_SEV ranges from } 0.5 \text { to } 0.9 \\
\text { and is discretized to four possible states. The expected value of this node was } \\
\text { estimated by Newcombe and MacDonald (1991). Uncertainty follows a normal } \\
\text { distribution with a standard deviation assumed for the purpose of this example. }\end{array}$ \\
\hline & BETA_DAM & - & $\begin{array}{l}\text { Damage function parameter: Parameter of the natural resource damage function. } \\
\text { BETA_DAM ranges from } 3.5 \text { to } 6 \text { and is discretized to five states. These values and the } \\
\text { marginal probabilities for each state were assumed for the purpose of the example. }\end{array}$ \\
\hline & ECON_VALUE_FISHERY & $\$$ & $\begin{array}{l}\text { Fishery damage cost: Economic cost of closing the fishery as a result of high PCB } \\
\text { concentrations. ECON_VALUE_FISHERY ranges from } \$ 0 \text { to } 10 \text { million. Uncertainty in } \\
\text { this variable may arise from lack of knowledge about natural resource values. The } \\
\text { values and marginal probabilities for this node are assumed for the purpose of the } \\
\text { example. }\end{array}$ \\
\hline
\end{tabular}




\begin{tabular}{|c|c|c|c|}
\hline Type & Symbol & Units & Description \\
\hline \multirow{6}{*}{ SDN } & $\mathrm{R}$ & - & $\begin{array}{l}\text { Resuspension rate: The percent of material removed from the navigation channel that } \\
\text { is suspended in the water column and available for transport. In general, cutterhead } \\
\text { dredgers are assumed to result in lower resuspension rates than bucket dredgers. } R \\
\text { ranges from } 0 \text { to } 1.2 \text { percent (Hayes et al. 2007) and is discretized to six possible } \\
\text { states. The conditional probability for each node state is based on best professional } \\
\text { judgment. }\end{array}$ \\
\hline & PROD_RATE & $\mathrm{m}^{3} / \mathrm{hr}$ & $\begin{array}{l}\text { Production rate: The rate at which sediment is removed from the sediment bed ( } \mathrm{m}^{3} / \mathrm{hr} \text { ). } \\
\text { PROD_RATE ranges from } 0 \text { to } 1150 \mathrm{~m}^{3} / \mathrm{hr} \text { and is discretized to nine possible states. } \\
\text { The production rate for cutterhead dredgers is generally higher and more predictable } \\
\text { than those for bucket dredgers. The expected sediment removal rate for a bucket } \\
\text { dredger is estimated to be } 638 \mathrm{~m}^{3} / \mathrm{hr} \text { and, for a cutterhead dredger, is estimated to be } \\
879 \mathrm{~m}^{3} / \mathrm{hr} \text {. Uncertainty in production rates is a function of operator efficiency, } \\
\text { mechanical reliability, and the potential for encountering debris in the material to be } \\
\text { dredged. The distribution of probabilities is assumed for the purpose of example, but } \\
\text { reflects engineering judgment regarding production rates. }\end{array}$ \\
\hline & DREDGER_COST_DAY & \$/day & $\begin{array}{l}\text { Dredger contract cost: The cost of leasing the dredger for one day. DREDGER_COST } \\
\text { ranges from } 0 \text { to } 90,000 \$ / \text { day and is discretized to four possible states. It is assumed } \\
\text { that the cost of leasing the bucket dredger will be slightly less expensive than the } \\
\text { cutterhead dredger. DREDGER_COST is uncertain because rates vary with the market } \\
\text { demand for dredger equipment. Potential costs and their probabilities are assumed for } \\
\text { the purpose of this example. }\end{array}$ \\
\hline & SHIP_SAV_TON & $\$ /$ ton & $\begin{array}{l}\text { Shipping cost savings: The navigation cost savings arising from increases in limiting } \\
\text { depth. SHIP_SAV_TON ranges from } 0 \text { to } 2 \$ / \text { ton and is discretized to five possible } \\
\text { values. Shipping cost savings are the result of increases in limiting depth that enable } \\
\text { ships with deeper drafts to pass through the navigation channel. If no dredging occurs, } \\
\text { no cost savings are realized. Shipping cost savings are identical under each dredging } \\
\text { alternative. State probabilities have been assumed for the purpose of this example. }\end{array}$ \\
\hline & DISPOSAL_COST & $\$ / m^{3}$ & $\begin{array}{l}\text { Dredged material disposal cost: The cost of disposing of one cubic meter of dredged } \\
\text { material. DISPOSAL_COST ranges from } 0 \text { to } 10 \$ / \mathrm{m}^{3} \text { and is discretized to five possible } \\
\text { states. This cost depends upon the mode of disposal. CAD disposal tends to be } \\
\text { cheaper because sediment is transported to the CDF by barge and dumped where it } \\
\text { settles into the CAD pit. CAD prices range from } \$ 2-6 / \mathrm{m}^{3} \text {. CDF disposal prices range } \\
\text { from } \$ 6-10 \$ / \mathrm{m}^{3} \text {. CDF disposal is more expensive because it involves additional slurry } \\
\text { pumping costs. Potential costs and their probabilities have been assumed for the } \\
\text { purpose of example, but reflect a typical range of dredged material disposal costs. }\end{array}$ \\
\hline & D_VOL & $m^{3}$ & $\begin{array}{l}\text { Dredged material volume: Volume of sediment to be removed from the navigation } \\
\text { channel. In this example, D_VOL does not vary across the decision alternatives. There } \\
\text { are no edges toward or away from this node because it is a constant. In practice, } \\
\text { D_VOL would be estimated through surveys of the channel prior to contracting with the } \\
\text { dredger and would be a well-known value. In this example, the estimate of dredge } \\
\text { volume is calculated from sediment depth }(0.5 \mathrm{~m}) \text { and dimensions of the channel } \\
\text { segment. }\end{array}$ \\
\hline \multirow{2}{*}{ EFN } & V_S & $\mathrm{m} / \mathrm{s}$ & $\begin{array}{l}\text { Particle settling velocity: The velocity at which suspended sediment settles out of the } \\
\text { water column. V_S is discretized to three possible values, and conditional probabilities } \\
\text { were based on DREDGE model runs varying PCT_FINES and DD_INSITU. }\end{array}$ \\
\hline & TSS_WC_BAY & $\mathrm{mg} / \mathrm{L}$ & $\begin{array}{l}\text { Total suspended solid concentration in the water column in unimpacted areas of the } \\
\text { bay: Areas of the bay that are outside of mixing zone areas will have water column total } \\
\text { suspended solids concentrations equivalent to background (TSS_BG). }\end{array}$ \\
\hline
\end{tabular}




\begin{tabular}{|c|c|c|c|}
\hline Type & Symbol & Units & Description \\
\hline \multirow{5}{*}{ EFN } & TSS_WC_CHNL & $\mathrm{mg} / \mathrm{L}$ & $\begin{array}{l}\text { Total suspended solid concentration in the water column in vicinity of the channel: TSS } \\
\text { water column concentration in the channel mixing zone. CPTs were developed for this } \\
\text { node by post-processing output of } 24 \text { DREDGE model runs. DREDGE is a USACE model } \\
\text { that simulates the transport of suspended sediment and other water quality } \\
\text { constituents. }\end{array}$ \\
\hline & TSS_WC_CAD & $\mathrm{mg} / \mathrm{L}$ & $\begin{array}{l}\text { Total suspended solids concentration in the CAD pit mixing zone: CPTs were developed } \\
\text { for this node by post-processing the output of } 96 \text { STFATE model runs. STFATE is a } \\
\text { USACE model that simulates the short-term fate of dredged material disposed of in } \\
\text { open water. }\end{array}$ \\
\hline & TSS_WC_CDF & $\mathrm{mg} / \mathrm{L}$ & $\begin{array}{l}\text { Total suspended solids concentration in the CDF mixing zone: CPTs were developed by } \\
\text { post-processing the outputs of } 192 \text { SETTLE model runs. SETTLE is a USACE model for } \\
\text { estimating sediment retention in CDFs and evaluating CDF storage requirements. }\end{array}$ \\
\hline & PCB_SED_CHNL_MZ & $\mathrm{mg} / \mathrm{Kg}$ & $\begin{array}{l}\text { Concentration of PCBs attached to suspended sediment in the channel mixing zone: } \\
\text { PCB concentrations were estimated by post-processing the results of } 24 \text { USACE } \\
\text { DREDGE model runs. DREDGE is a USACE model that simulates the fate and transport } \\
\text { of suspended sediment and other water quality constituents. }\end{array}$ \\
\hline & PCB_SED_CAD_MZ & $\mathrm{mg} / \mathrm{Kg}$ & $\begin{array}{l}\text { Concentration of PCBs attached to suspended sediment at the CAD pit mixing zone: } \\
\text { Deposition rates and sediment concentrations were estimated by post-processing the } \\
\text { results of } 96 \text { STFATE model runs. STFATE is a USACE model that simulates the short- } \\
\text { term fate of dredged material disposed of in open water. }\end{array}$ \\
\hline
\end{tabular}

Sediment plumes in the vicinity of the navigation channel were simulated using the fate and transport module in USACE's DREDGE model (Hayes and Je 2000). The model estimates sediment concentration using a twodimensional, depth-averaged advection dispersion equation:

$$
\mathrm{C} \_\mathrm{xy}=\left(\frac{\mathrm{M} \_\mathrm{R}}{\mathrm{U} \cdot \mathrm{D} \cdot \sqrt{4 \pi \cdot \mathrm{K} \_\mathrm{y} \cdot \frac{\mathrm{x}}{\mathrm{U}}}}\right) \exp \left(\left(\frac{-\mathrm{y}^{2}}{4 \cdot \mathrm{K} \_\mathrm{y} \cdot \frac{\mathrm{x}}{\mathrm{U}}}\right)\left(\frac{\mathrm{V} \_\mathrm{S}}{\mathrm{U} \cdot \mathrm{D}}\right)\right)+\mathrm{C} \_\mathrm{BG}
$$

C_xy is the concentration at grid coordinates $x$ and $y$, $\mathrm{U}$ is the longitudinal current velocity, $\mathrm{D}$ is the estuary depth, and $\mathrm{K} \_\mathrm{y}$ is the lateral dispersion coefficient, $\mathrm{K} \_\mathrm{y}=0.06 \cdot \mathrm{D} \cdot \mathrm{U}$. Fixed input parameters used in TSS transport modeling (i.e., those parameters that were specified in the DREDGE model but that do not appear in the Bayesian network and therefore were not varied in model runs to generate CPTs) are as summarized in Table 4. The DREDGE model was run 24 times varying the value of those variables in the DREDGE model that are represented by network nodes. For every possible combination of parent node states, conditional probabilities for the TSS_WC_CHNL node were obtained by calculating the fraction of $200 \mathrm{~m}^{2}$ grid cells within the channel mixing zone with predicted concentrations in the range of each TSS_WC_CHNL concentration interval. 
Table 4. Fixed parameter values used in the DREDGE model.

\begin{tabular}{|l|l|l|}
\hline DREDGE model parameter & Value & Units \\
\hline Longitudinal average velocity & 0.2 & $\mathrm{~m} / \mathrm{s}$ \\
\hline Lateral dispersion coefficient & 480 & $\mathrm{~cm}^{2} / \mathrm{s}$ \\
\hline Average depth & 4 & $\mathrm{~m}$ \\
\hline Lateral grid cells (number) & 25 & - \\
\hline Longitudinal grid cells (number) & 50 & - \\
\hline Grid cell width & 6 & $\mathrm{~m}$ \\
\hline Grid cell length & 50 & $\mathrm{~m}$ \\
\hline Specific gravity of solids & 2.65 & - \\
\hline
\end{tabular}

TSS Concentrations at the CAD Pit Mixing Zone (TSS_WC_CAD)

The disposal of dredged material in a CAD pit will result in suspension and dispersal of sediment in the water column. Sediment plumes created by disposal of mechanically dredged material in a CAD pit were simulated using USACE's STFATE model (USEPA, USACE 1998). Because the size of the CAD pit in this example is relatively small, the disposal of hydraulically dredged material in the CAD pit was not modeled. Hydraulically dredged material has a relatively high bulking factor, making this mode of disposal infeasible considering the volume of the CAD pit.

STFATE models disposal of dredged material from a hopper barge by separating the behavior of the material during disposal into three phases: convective descent, dynamic collapse, and passive transport-dispersion. Convective descent occurs when the disposal cloud falls under the influence of gravity after the material has been dumped. Dynamic collapse occurs when the descending cloud either impacts the bottom or arrives at a level of neutral buoyancy where descent is retarded and horizontal spreading dominates. Passive transport-dispersion begins when transport and spread of the disposal cloud is more heavily influenced by ambient currents and turbulence than by the dynamics of the disposal operation.

Documentation of the STFATE model and a discussion of default STFATE model inputs for several example dredged material discharge scenarios are provided in The Inland Testing Manual (USEPA and USACE 1998). For this study, TSS modeling was performed using default parameters from the "Example-Barge Screen MPRSA 103.DUI" input file. Table 5 lists default parameters that were modified specifically for use in this case 
study. TSS modeling in STFATE is a time-dependent process, unlike the steady-state TSS modeling performed in the transport module of DREDGE. This complicated the compilation of TSS results, as TSS concentrations at each grid location were superimposed at time steps that varied according to dredging production rates, which affected the interval between barge placements. For every possible combination of parent node states, conditional probabilities for the TSS_WC_CAD node were obtained by calculating the fraction of $1200 \mathrm{~m}^{2}$ grid cells within the CAD pit mixing zone with predicted concentrations in the range of each TSS_WC_CAD concentration interval.

Table 5. Fixed parameter values used in the STFATE model.

\begin{tabular}{|l|l|l|}
\hline STFATE model parameter & Value & Units \\
\hline Barge capacity & 765 & $\mathrm{~m}^{3}$ \\
\hline Length of barge bin & 27.4 & $\mathrm{~m}$ \\
\hline Width of barge bin & 11.0 & $\mathrm{~m}$ \\
\hline Pre-disposal barge draft & 3.0 & $\mathrm{~m}$ \\
\hline Post-disposal barge draft & 1.2 & $\mathrm{~m}$ \\
\hline Barge emptying time & 30 & $\mathrm{~s}$ \\
\hline CAD pit length & 76.2 & $\mathrm{~m}$ \\
\hline CAD pit width & 76.2 & $\mathrm{~m}$ \\
\hline Average depth & 12.2 & $\mathrm{~m}$ \\
\hline Lateral grid cells (number) & 30 & - \\
\hline Longitudinal grid cells (number) & 60 & - \\
\hline Grid cell width & 12 & $\mathrm{~m}$ \\
\hline Grid cell length & 100 & $\mathrm{~m}$ \\
\hline Depth at placement site & 4.0 & $\mathrm{~m}$ \\
\hline
\end{tabular}

TSS Concentrations at the CDF Mixing Zone (TSS_WC_CDF)

CDFs are designed to provide sufficient hydraulic retention time to permit the larger suspended solids to settle out of the water column (Hayes and Schroeder 1992). In this example, it was assumed that the CDF is just large enough to meet initial storage requirements, allowing larger particles to settle out in the CDF and smaller particles to be discharged in supernatant effluent. Since mechanical dredging tends to produce a slurry with a relatively small bulking factor when compared to hydraulically dredged material, it was assumed that no effluent from the CDF would occur under the Bucket_CDF alternative. USACE's SETTLE model was used to 
estimate CDF effluent flow rates and TSS concentrations in effluent from the CDF for the Cutterhead_CDF alternative. Fixed parameters used in this application of the SETTLE model are listed in Table 6.

Table 6. Fixed parameter values used in the SETTLE model.

\begin{tabular}{|l|l|l|}
\hline SETTLE model parameter & Value & Units \\
\hline CDF size & 22 & acres \\
\hline Pipeline velocity & 15 & $\mathrm{ft} / \mathrm{s}$ \\
\hline CDF dike height & 5.44 & $\mathrm{ft}$ \\
\hline Average CDF dike freeboard & 1 & $\mathrm{ft}$ \\
\hline Depth withdrawal at weir & 1 & $\mathrm{ft}$ \\
\hline Ponded depth & 0.05 & $\mathrm{ft}$ \\
\hline Specific gravity of solids & 2.65 & - \\
\hline
\end{tabular}

The mass loading rates obtained from SETTLE were used as inputs to the transport module of DREDGE to estimate TSS plume concentrations. Because suspended solids in the supernatant effluent discharged from the $\mathrm{CDF}$ are assumed to be small, it was assumed that none of these particles would settle in the CDF mixing zone. These particles remain in suspension until they are flushed from the estuary or diluted with background TSS to the point where their effects are negligible (USACE, In Prep). For every possible combination of parent node states, conditional probabilities for the TSS_WC_CDF node were obtained by calculating the fraction of $300 \mathrm{~m}^{2}$ grid cells within the CDF effluent mixing zone with predicted concentrations in the range of each concentration interval.

\section{PCB Concentrations in Sediment}

If contaminants are attached to sediment particles, contaminants may become dispersed to a larger portion of the water body as sediment settles out of the dredge and disposal plumes. In this study, the sediment deposition and sediment PCB concentrations were modeled to determine the bio-available quantity of PCBs in the estuary and assess the environmental risks associated with each dredging and dredged material disposal alternative. Sediment PCB concentrations in areas of sediment deposition were modeled for each alternative for all possible states of parent nodes. The range of potential sediment PCB concentrations is discretized to six possible states. 
Sediment deposition and sediment PCB concentrations were not modeled at the CDF mixing zone. For the Bucket_CDF alternative, it was assumed that the $\mathrm{CDF}$ would have sufficient capacity to retain all material and free water deposited in the CDF because mechanically dredged sediment has a low bulking factor. For the Cutterhead_CDF alternative, it was assumed that supernatant effluent discharged from the CDF would contain only fine-grained sediment that would remain in suspension and become dispersed in the water column without settling in the estuary.

Sediment PCB Concentrations in the Channel Mixing Zone (PCB_SED_CHNL_MZ)

The mass of sediment and PCBs deposited in the channel mixing zone for bucket and cutterhead dredging alternatives was calculated using the transport module of DREDGE. The particulate associated PCB mass was modeled using the contaminant module of DREDGE with an internally calculated linear partitioning coefficient of 12,567. The steady state dredge plume model was applied to estimate the mass of sediment deposited in each grid cell and a particle-associated PCB concentration allowing six hours of tidal flow in the flood and ebb directions. The dredger was moved down the navigation channel by a stepping distance, reflecting the length of the channel and the duration of the dredging project until the dredger reached the end of the channel, signifying the completion of the dredging project. The results of these simulations were superimposed on each other and the sediment PCB concentration was calculated from PCB and TSS depositional masses. The thickness of the deposited sediment was calculated from the grid cell size and the mass of sediment deposited assuming a depositional dry density (DD_RES) of $300 \mathrm{~kg} / \mathrm{m}^{3}$ (USACE, In Prep).

PCBs are hydrophobic $\left(K_{o w}=\sim 1.1 \mathrm{E} 6\right.$ (Hayes and Je 2000)). Therefore, it was assumed that the majority of the in-situ PCB mass would remain associated with resuspended sediment particles and that the dissolved fraction of PCBs would be negligible. PCBs that are attached to sediment and that settle out of the water column are deposited at the bottom of the bay and are considered bio-available. A biologically available mixed layer of four centimeters was assumed for all mixing zones (Clarke et al. 2001).

A sediment-associated PCB concentration was calculated in the channel for use in bio-uptake calculations. If the depositional thickness of sediment (DEP_THK) was greater than or equal to four centimeters, the average PCB 
concentration of the deposited sediment was used in bio-uptake calculations. If DEP_THK was less than four centimeters, then the average bioavailable PCB sediment concentration in a grid cell (PCB_SED_xy) was calculated as follows:

$$
\text { PCB_SED_xy }=\frac{\text { MASS_PCB_xy }}{\text { DD_RES } \cdot \text { DEP_THK }+\left(4-D E P \_T H K\right) \cdot D D \_I N S I T U}
$$

where MASS_PCB_xy $(\mathrm{kg})$ is the total mass of PCB in the grid cell at grid coordinates $x$ and $y$. This equation necessarily assumes that the top four centimeters of the in-situ material is clean (no PCB contamination) as was stated in the example formulation. Thus, for depositional thicknesses of less than four centimeters, varying DD_INSITU values will affect PCB_SED_xy.

Sediment PCB Concentrations in the CAD Pit Mixing Zone (PCB_SED_CAD_MZ)

The USACE STFATE model (USEPA/USACE 1998) was used to simulate the deposition of sediment resulting from the placement of mechanically dredged material at the $\mathrm{CAD}$ site. Deposition modeling runs were conducted using the default and scenario-specific parameters described in Table 6. Deposition results for the dredging operation were superimposed and sediment masses summed. PCB masses in the grid cells were calculated using linear partitioning theory. The bio-available sediment associated PCB concentration was estimated as described for PCB_SED_CHNL_MZ.

\section{Economic Damages to the Fishery}

Economic damages to the fishery arise from the exposure of fish to suspended sediment in the water column and to PCBs in sediment deposits.

Economic Damages from Fish Exposure to Suspended Sediment (DAM_RESUSP)

Fish response to TSS is estimated for each of the four zones in the estuary. The fish exhibit a negative response to high TSS concentrations. The response exhibited depends on the exposure concentration, the duration of exposure, and the physiological sensitivity of the species. Responses range from behavioral avoidance to physiological stress and mortality. The sea 
bass in this example are assumed to be bottom dwelling, site tenacious and uniformly distributed in the bay. Exposures were calculated, assuming a twelve-hour dredging day and a twelve-hour tidal cycle, resulting in an exposure period of six hours per day. The fish response to TSS concentrations is predicted using an empirical relationship as estimated by Newcombe and MacDonald (1991) for a generic fish species:

$$
\text { SEV_Z=BETA_SEV } \cdot \ln \left(T S S \_W C \_B A Y \cdot D \_H R S\right)+2.179
$$

The dependent variable SEV_Z is an index of the severity of impact on fish caused by TSS in zone $\mathrm{Z}$ (e.g., BAY, CDF, CAD, CHNL). The SEV index, shown in Table 7, is a generalization of the index provided by Newcombe and MacDonald (1991). ${ }^{1}$ BETA_SEV was empirically estimated by Newcombe and MacDonald, who obtained a mean value of 0.738 . These authors do not report uncertainty in the BETA_SEV estimate, so a distribution has been assumed for the purpose of this example. The duration of exposure, D_HRS, is assumed to be six hours because the fish are territorial and the direction of the dredge plume from the dredge will be controlled by semi-diurnal tidal flows in and out of the bay. Rising tides will direct the plume into the bay and ebbing tides will direct the plume toward open water.

Economic damages to the commercial fishery in the estuary caused by each twelve-hour day of dredging depend upon the severity of behavioral and physiological impacts in each of the zones. As the severity of behavioral and physiological impacts increases, fish will lose weight and as mortality increases, the population will decline and catch-effort will increase. Economic damages from TSS in each zone are estimated from SEV:

$$
\mathrm{DAM} \_\mathrm{Z}=\mathrm{a}_{\mathrm{Z}} \mathrm{SEV} \_\mathrm{Z}^{\mathrm{BETA} \_\mathrm{DAM}}
$$

where az is the fraction of the area in the estuary that is accounted for by each designated mixing zone $\left(a_{\mathrm{CAD}}=0.0061, a_{\mathrm{CDF}}=0.0708, a_{\mathrm{PLUME}}=\right.$ 0.0708 , and $\left.a_{\mathrm{BG}}=0.8523\right)$. The areas of the bay sum to one. SEV_Z is the index of fish response to TSS in that zone, and BETA_DAM is an uncertain parameter value assumed for the purpose of example.

1 While Newcombe and MacDonald's SEV index is used for the purpose of this example, its validity has been questioned because it suggests that background TSS concentrations can cause behavioral and even moderate physiological impacts (Wilber and Clarke 2001). It seems more likely that fish would be well adapted to background conditions. 
Table 7. Index for assessing suspended sediment impacts on fish (SEV Index from Newcombe and MacDonald (1991)).

\begin{tabular}{|c|c|c|c|}
\hline SEV index & Description of effect & $\begin{array}{l}\text { Modified SEV } \\
\text { index }\end{array}$ & Description of effect \\
\hline 1 & Increased coughing rate & \multirow{5}{*}{$0.0-5.5$} & \multirow{5}{*}{ No effect / behavioral effect } \\
\hline 2 & Alarm reaction, avoidance reaction & & \\
\hline 3 & Avoidance response, abandonment of cover & & \\
\hline 4 & Reduction in feeding rate & & \\
\hline 5 & Impaired homing & & \\
\hline 6 & Poor condition of organism & $5.5-6.5$ & Physiological stress \\
\hline 7 & Moderate habitat degradation & $6.5-7.5$ & Habitat degradation \\
\hline 8 & Physiological stress and histological changes & $7.5-8.5$ & Major physiological effects \\
\hline 9 & Reduction in growth rates & $8.5-9.5$ & Reduced growth rate, density \\
\hline 10 & 0-20 \% Mortality & \multirow{5}{*}{$9.5-14.5$} & \multirow{5}{*}{ Mortality } \\
\hline 11 & 20-40\% Mortality & & \\
\hline 12 & 40-60\% Mortality, severe habitat degradation & & \\
\hline 13 & $60-80 \%$ Mortality & & \\
\hline 14 & Greater than $80 \%$ mortality & & \\
\hline
\end{tabular}

Damages were limited to $\$ 30,000$ per day. As fish were assumed to be uniformly distributed in the bay, the aggregate damage to the fishery is the sum of damage in the four impact zones. Damages from TSS are estimated in two nodes: DAM_TSS and DAM_TSS_BG.DAM_TSS is the areaweighted sum of economic damages in the estuary and DAM_TSS_BG is the economic damage caused by exposure to background TSS concentrations that would have occurred in the absence of any dredging activity.

Economic damages to the fishery are a function of the duration of dredging activity (DURATION), which is calculated from the hourly production rate (PROD_RATE) and dredge volume (D_VOL):

$$
\text { DURATION }=\frac{\text { D_VOL }}{12 \cdot \text { PROD_RATE }}
$$

This assumes that dredging occurs over a 12-hour period each day. Total economic damages to the fishery from the resuspension of sediment increase with the duration of the dredging activity. Damage from TSS resuspension is: 


$$
\text { DAM } \_ \text {RESUSP }=\text { DURATION } \cdot\left(\text { DAM } \_T S S-D A M \_T S S \_B G\right)
$$

The difference between the effect of elevated TSS concentrations caused by dredging and disposal (DAM_TSS) and the baseline effect of background concentrations that would have occurred in the absence of dredging (DAM_TSS_BG) is the daily economic damage caused by TSS resuspension.

\section{Economic Damages from Fish Exposure to PCBs}

Sediments accumulated in the navigation channel are contaminated with PCBs originating from legacy industrial sites that contribute runoff to the estuary. Contaminated sediments accumulate preferentially in the navigation channel. PCB concentrations in channel sediment are uncertain, but sampling and analysis reveals a PCB concentration of o to $0.5 \mathrm{mg} / \mathrm{L}$ with a mean concentration of $0.25 \mathrm{mg} / \mathrm{L}$. Dredging will release sediments into the water column during both removal and some disposal options. PCBs will be distributed in the estuary in sediment plumes and will be deposited on the sediment bed, where they will potentially be bio-available and therefore will accumulate in fish tissue.

Given an average concentration of PCBs in the mixed layer, the steadystate concentration of PCBs in fish tissue at any location in the estuary is approximated by:

$$
\text { PCB_FISH_Z }=\frac{(\text { PCB_DEP_Z } \cdot \text { BSAF.LIPIDS })}{\text { PCT_OC }}
$$

where PCB_FISH_Z is the PCB concentration in estuary zone Z (e.g., CHNL, CAD, CDF, etc.), PCB_DEP_Z is the concentration of PCBs in sediment at estuary zone Z, LIPIDS is the lipid content of fish tissue (as a percent of body weight), and PCT_OC is the percent of organic carbon in sediment. Economic damages to the fishery are realized when fish tissue PCB concentrations exceed $0.2 \mathrm{mg} / \mathrm{kg}$ because the fishery will be closed in accordance with environmental health and safety regulations (USEPA 2000).

\section{Dredging Cost (OP_COST_TOTAL)}

Dredgers are leased at a fixed daily rate between $\$ 70,000$ and $\$ 90,000$ per day (DREDGER_COST_DAY), but this rate will not be known until the dredger is actually leased for the project at a fixed daily rate specified in the 
contract. Daily rates for leasing a dredger will be uncertain because daily rates fluctuate with the demand for dredgers. In general, cutterhead dredgers are more expensive to operate than bucket dredgers. The total cost of the dredging project (OP_COST_TOTAL) is a function of the volume of material to be removed from the channel (D_VOL), the type of dredging equipment used, and the duration of the dredging period in days (DURATION). Uncertainty in the cost arises from uncertainty in the duration of the dredging project and uncertainty in the cost of the dredger. Cutterhead dredgers tend to be more efficient under certain types of site conditions.

\section{Dredged Material Disposal Cost (DISP_COST_TOTAL)}

There is a cost for disposal of dredged material that varies with the method of disposal (DISPOSAL_COST, $\$ / \mathrm{m}^{3}$ ). In general, it is more expensive to dispose of dredged material in a CDF. Mean CDF disposal costs are assumed to be $\$ 7 / \mathrm{m}^{3}$ while mean CAD disposal costs are $\$ 3 / \mathrm{m}^{3}$. The calculated disposal costs account for the sediment that is lost to sediment resuspension during dredging:

$$
\text { DISP_COST_TOTAL }=\mathrm{D} \_V O L \cdot\left(1-\frac{\mathrm{R}}{100}\right) \cdot \text { DISPOSAL_COST }
$$

Uncertainty in the total disposal cost arises from uncertainty in the resuspension rates and uncertainty in the unit cost of disposal in the planning stages of the project.

\section{Economic Benefits to Navigation (SHIP_SAV_TOTAL)}

Shipping cost savings are realized when the limiting depth of the channel is increased to allow ships with deeper drafts to pass through the channel. This enables ships to carry more cargo and reduces the need to run with lighter loads or transfer cargo to smaller ships. Since the resulting limiting depth will be the same under each alternative, each alternative will result in the same amount of shipping cost savings per ton of cargo (SHIP_SAV_TON). Uncertainty in total shipping cost savings (SHIP_SAV_TOTAL) can be attributed to uncertainty in estimates of the shipping cost savings per ton and uncertainty in the tonnage of cargo that will actually be transported through the navigation channel (TONNAGE). TONNAGE is assumed to vary from year to year with economic conditions. Economic benefits to the shipping 
industry are generally expected to accrue for several years after dredging; however, to simplify this example, we consider only the single benefit period.

\section{Net Benefits of the Dredging Project (NET_BENEFIT)}

For the purpose of this example, only market values are considered in evaluating outcomes of the dredging alternatives. Non-market resource values, such as existence values for the fish population described in this analysis, are not considered. The net benefit of each alternative is the difference between estimated benefits and costs of the alternative - after considering the benefits to the shipping industry, the sediment removal and disposal costs, and the economic damages to the fishery. Economic damages to the fishery depend upon the concentration of PCBs in fish tissue. If PCB concentrations in fish tissue are less than $0.2 \mathrm{mg} / \mathrm{kg}$, the economic damages to the fishery are the marginal damages to the fishery from sediment resuspension:

NET_BENEFIT $=$ SHIP_SAV_TOTAL -

(DAM_RESUSP + DISP_COST_TOTAL + OP_COST_TOTAL)

If $\mathrm{PCB}$ concentrations in fish tissue are greater than or equal to $0.2 \mathrm{mg} / \mathrm{kg}$, the economic damages to the fishery arise from closure of the fishery, which has an expected cost of $\$ 5.96$ million per year.

$$
\begin{aligned}
& \text { NET_BENEFIT }=\text { SHIP_SAV_TOTAL }- \\
& (\text { ECON_VALUE_FISHERY }+ \text { DISP_COST_TOTAL }+ \text { OP_COST_TOTAL })
\end{aligned}
$$

If the fishery is closed, this closure is likely to last for several years. However, to simplify this problem for the purpose of illustrating the decision modeling approach, we consider only the single period calculation.

\section{Evaluation of Dredging and Dredged Material Disposal Alternatives}

Alternatives evaluation is accomplished by entering a finding into the decision node, updating the probabilities in the network using Bayes' rule, and calculating the NET_BENEFIT of each alternative. Software that uses highly efficient exact algorithms can perform these computations in a matter of seconds. Results are summarized in Table 8. The NET_BENEFIT under the No Dredging alternative is negative because there is a latent nonzero probability that PCB_FISH_BAY will exceed $0.2 \mathrm{mg} / \mathrm{kg}$. Even without 
dredging because bio-available concentrations of PCBs are present in navigation channel sediment. Given the available information, Cutterhead_CDF maximizes the expected monetary value (EMV) of the decision.

Table 8. Expected NET_BENEFIT of the alternatives.

\begin{tabular}{|c|c|c|c|}
\hline \multirow[b]{2}{*}{ Alternative } & \multicolumn{2}{|c|}{ NET_BENEFIT (\$, Million) } & \multirow{2}{*}{$\begin{array}{l}\text { Prob(PCB_FISH_BAY }>0.2 \\
\mathrm{mg} / \mathrm{kg})\end{array}$} \\
\hline & Mean & Std. dev. & \\
\hline No Dredging & -0.07 & 0.36 & 0.012 \\
\hline Bucket CAD & 1.77 & 4.00 & 0.163 \\
\hline Bucket CDF & 1.64 & 3.90 & 0.152 \\
\hline Cutterhead CDF & 2.18 & 4.00 & 0.152 \\
\hline
\end{tabular}




\section{Statistical Inference and Value of Information Analysis}

The decision model provides a tool for evaluating alternatives, a tool for statistical inference, and a tool for evaluating the benefits of acquiring additional information. This section of the paper demonstrates these different types of analysis focusing on a self-contained subset of the network that can be extracted without affecting probability estimates in extracted nodes. The existence of this network subspace is an artifact of the way that this particular graphical model has been structured. The demonstrations focus on this subspace because the effects of instantiation can be more easily visualized, but equivalent results could be obtained with the larger network as well.

The sub-model is illustrated in Figure 6. A new node (PCB_FISH_BAY > $0.2 \mathrm{mg} / \mathrm{kg}$ ) has been introduced into the network to calculate the probability that PCB concentrations in fish tissue will exceed standard for PCB concentrations in fish tissue. The No_Dredging alternative has been instantiated to assess the baseline probability of exceeding the standard prior to implementing any kind of dredging alternative. The baseline probability of exceeding the regulatory standard is 0.0113. If a dredging alternative would result in a probability of exceeding the standard that is greater than the maximum allowable probability of exceeding the standard, the decision rule is that the dredging alternative will not be implemented. This is an example of a risk-based standard for fish-tissue concentrations.

\section{Statistical Inference}

Bayesian networks can be used for both predictive and diagnostic statistical inference. Predictive inference is reasoning from information about the possible causes of an event to assess the probability of that event. Diagnostic inference is reasoning from effects to causes to assess the probability of potential causes. Predictive and diagnostic inference is demonstrated in the following sections of this report using the sub-model. 


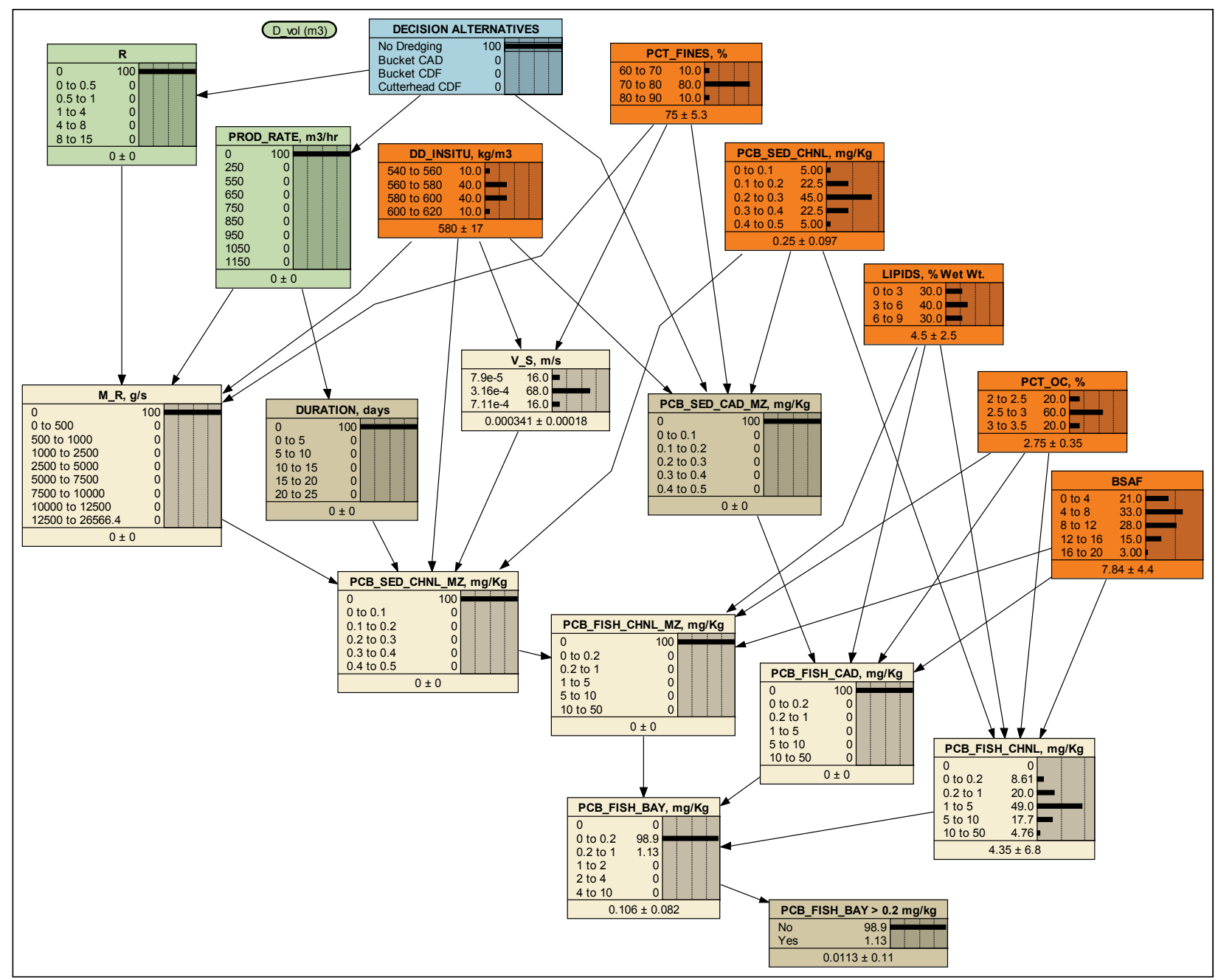

Figure 6. Subset of the decision model used for demonstration of statistical inference and VOI analysis. The No_Dredging alternative is instantiated to show the baseline probability of exceeding the regulatory limit of $0.2 \mathrm{mg} / \mathrm{kg}$ of PCBs in fish tissue.

\section{Predictive Inference}

The preceding decision analysis suggested that Cutterhead_CDF is the preferred alternative because it maximizes the expected net benefits of the project. By instantiating the Cutterhead_CDF alternative, it is possible to assess the effect of this alternative on the probability that PCB concentrations in fish tissue will exceed the critical concentration of $0.2 \mathrm{mg} / \mathrm{kg}$. Results show that Cutterhead_CDF increases the probability that PCB concentrations in fish tissue will exceed the critical concentration. The probability increases from 0.0113 under baseline conditions to 0.151 under Cutterhead_CDF. This is illustrated in Figure 7, which shows instantiation of Cutterhead_CDF in the sub-model. 


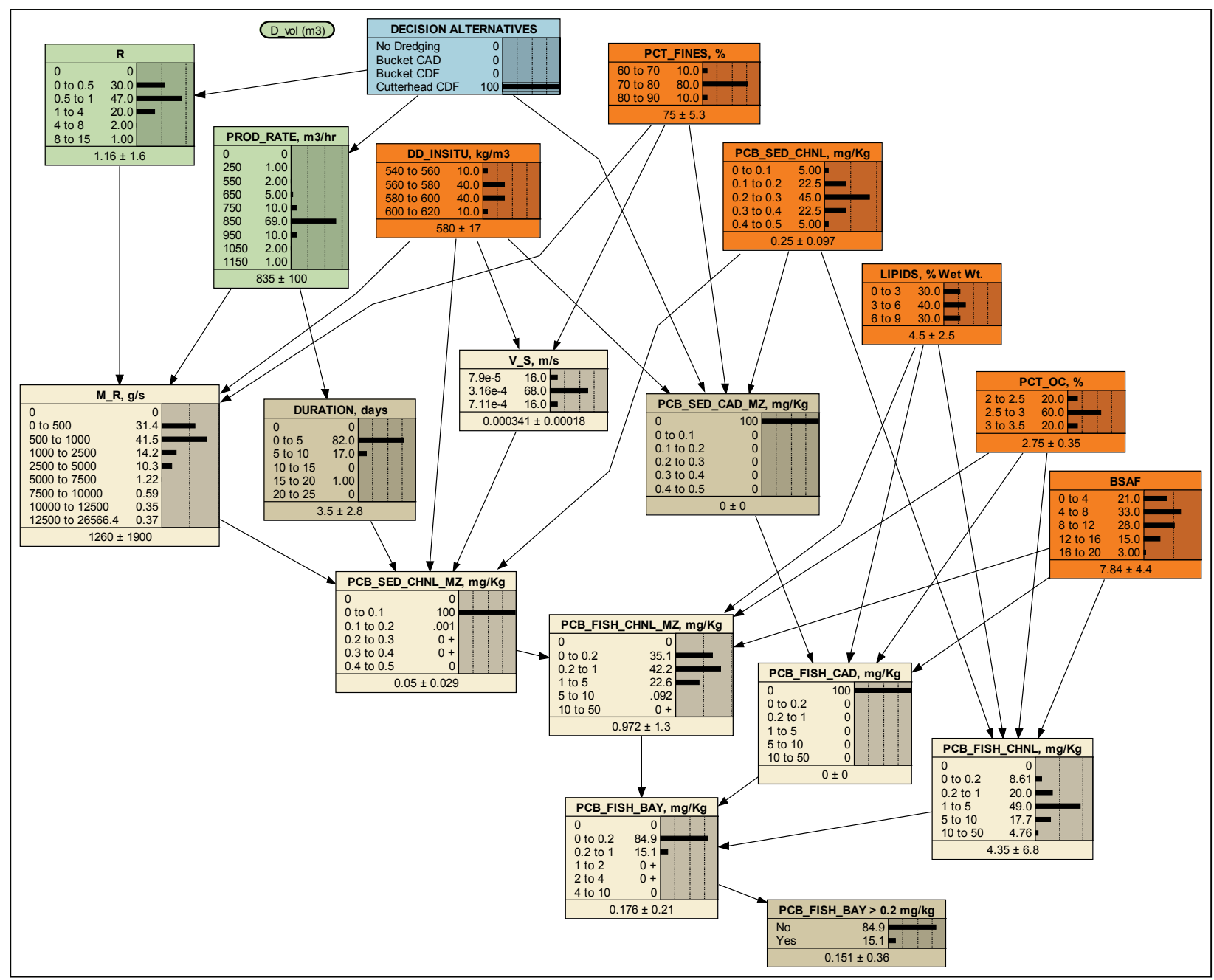

Figure 7. Subset of the decision model showing instantiation of the Cutterhead_CDF alternative. Cutterhead_CDF is instantiated to show how the probability of exceeding the maximum allowable concentration of PCBs in fish tissue would change relative to the baseline conditions.

There are several sources of uncertainty that influence the concentration of PCBs in fish tissue. This demonstration shows how the network might be used to assess what effect new information might have on the probability of exceeding the maximum allowable concentration of PCBs in fish tissue. The demonstration focuses on LIPIDS and PCT_OC. Uncertainty in these random variables may be reduced (or increased) by obtaining site-specific data. Information about lipids in sea bass tissue can be obtained by sampling fish from the estuary and analyzing fish tissue in the laboratory. Similarly, information about the organic carbon content of sediment in the estuary can be obtained by laboratory analysis of sediment sampled from the estuary. 
The prior probability distribution for the LIPIDS variable is from data published by Kwon et al. (2007). Suppose that the decision maker were to conduct a site investigation to obtain more information about the LIPIDS variable with hopes of reducing uncertainty. Suppose that the results of this study were to yield hard evidence that the sea bass fish tissue in the Port Essayons estuary is $3-6 \%$ lipids. This information can be represented in the model by instantiating the LIPIDS node as shown in Figure 8. Instantiation of a node causes all probabilities in the network to be updated using Bayes' rule. The posterior probabilities in Figure 8 can be compared to those in Figure 7 to see how instantiation of the LIPIDS node affects other nodes in the network (PCB_FISH_CHNL_MZ, PCB_FISH_CHNL, PCB_FISH_BAY, and PCB_FISH_BAY $>0.2 \mathrm{mg} / \mathrm{kg}$ ). Knowing that sea bass fish tissue has a lipid content of $3-6 \%$ has reduced the probability that the regulatory standard for fish tissue PCB concentrations will be exceeded under the Cutterhead_CDF alternative from 0.151 to 0.141.

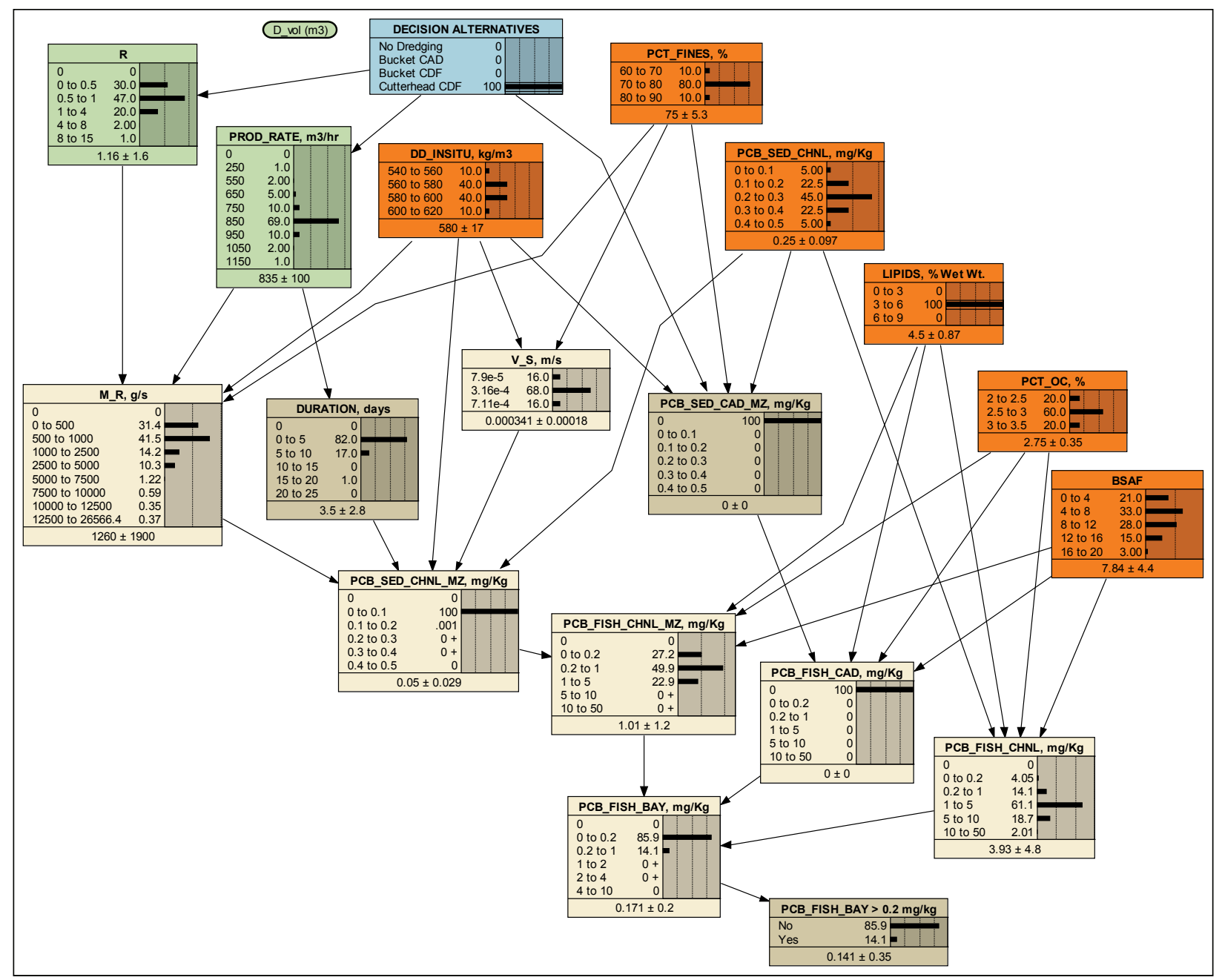

Figure 8. Predictive inference with instantiation of the LIPIDS node. 
Suppose that, after obtaining information about LIPIDS, the port authority decides to obtain additional site-specific information on the organic carbon content of sediment (PCT_OC) in Port Essayons estuary. The prior probability distribution for the PCT_OC node is from USACE's Dredged Material Physical Properties Database (USACE, In Prep). Suppose that laboratory analysis reveals hard evidence that PCT_OC is actually between 3 and 3.5. This evidence can be introduced into the network by instantiating the PCT_OC node. Instantiation has the effect of updating what are now the prior probabilities shown in Figure 8 to obtain the posterior probabilities that are shown in Figure 9. The posterior probability of exceeding the maximum allowable concentration of PCBs in fish tissues is now 0.0969 .

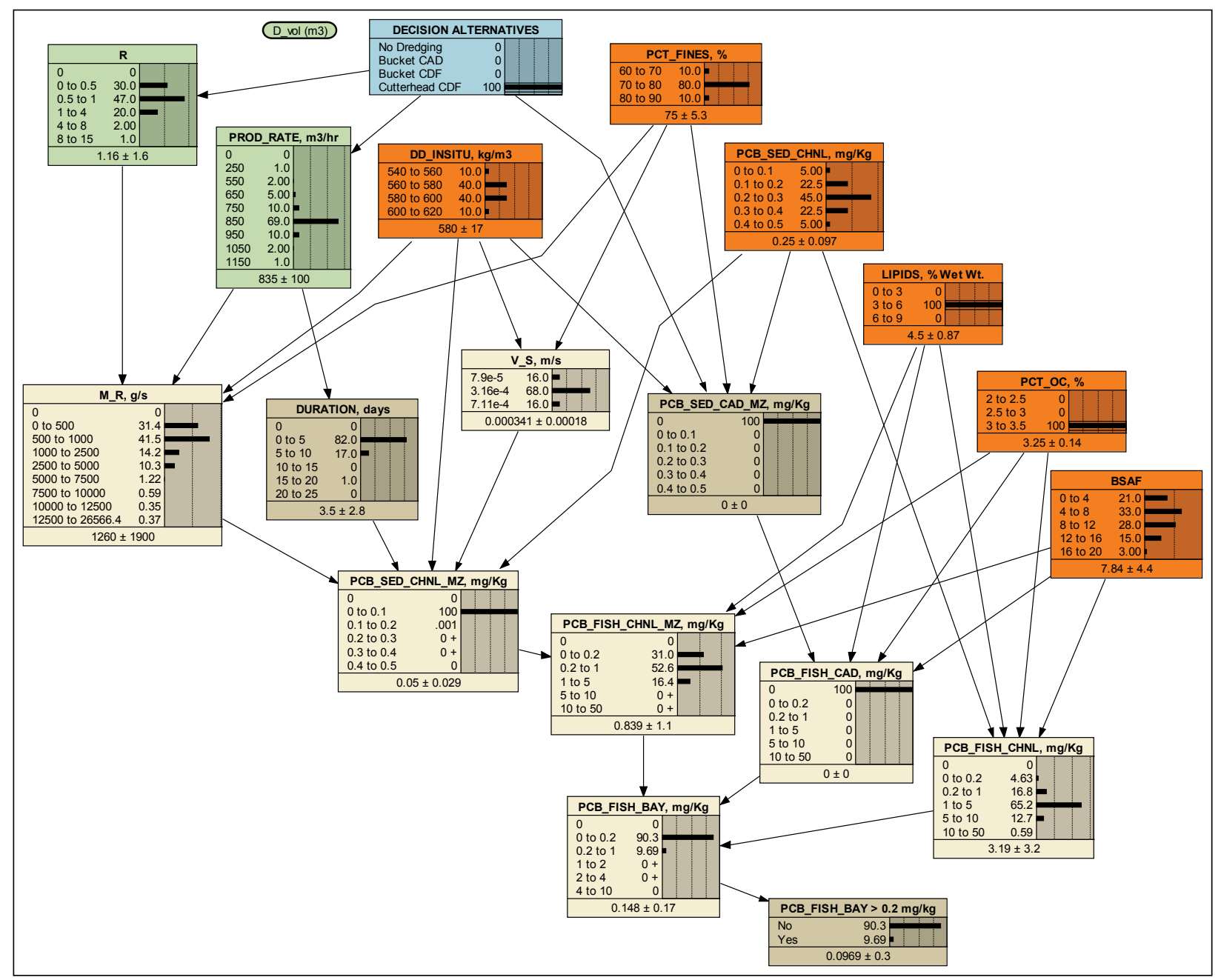

Figure 9. Predictive inference with instantiation of the LIPIDS and PCT_OC nodes. 


\section{Diagnostic Inference}

Diagnostic inference is reasoning from observed effects to possible causes.

For this demonstration, suppose the port authority took a different approach to obtaining information about the site. Rather than obtaining information on SDNs and SCNs, suppose the port authority obtained information about predicted nodes to obtain posterior probability distributions for SCNs. These updated probability distributions might subsequently be used to predict the effects of Cutterhead_CDF. For example, the Bayesian network predicts the concentration of PCBs in fish tissue in the channel (PCB_FISH_CHNL). If the port authority obtained a sample of sea bass from the estuary and obtained hard evidence that PCB concentrations in sea bass fish tissue were between 0.2 and $1 \mathrm{mg} / \mathrm{kg}$, the probabilities in the network could be updated by instantiating the PCB_FISH_BAY node, as shown in Figure 10. This analysis is done with

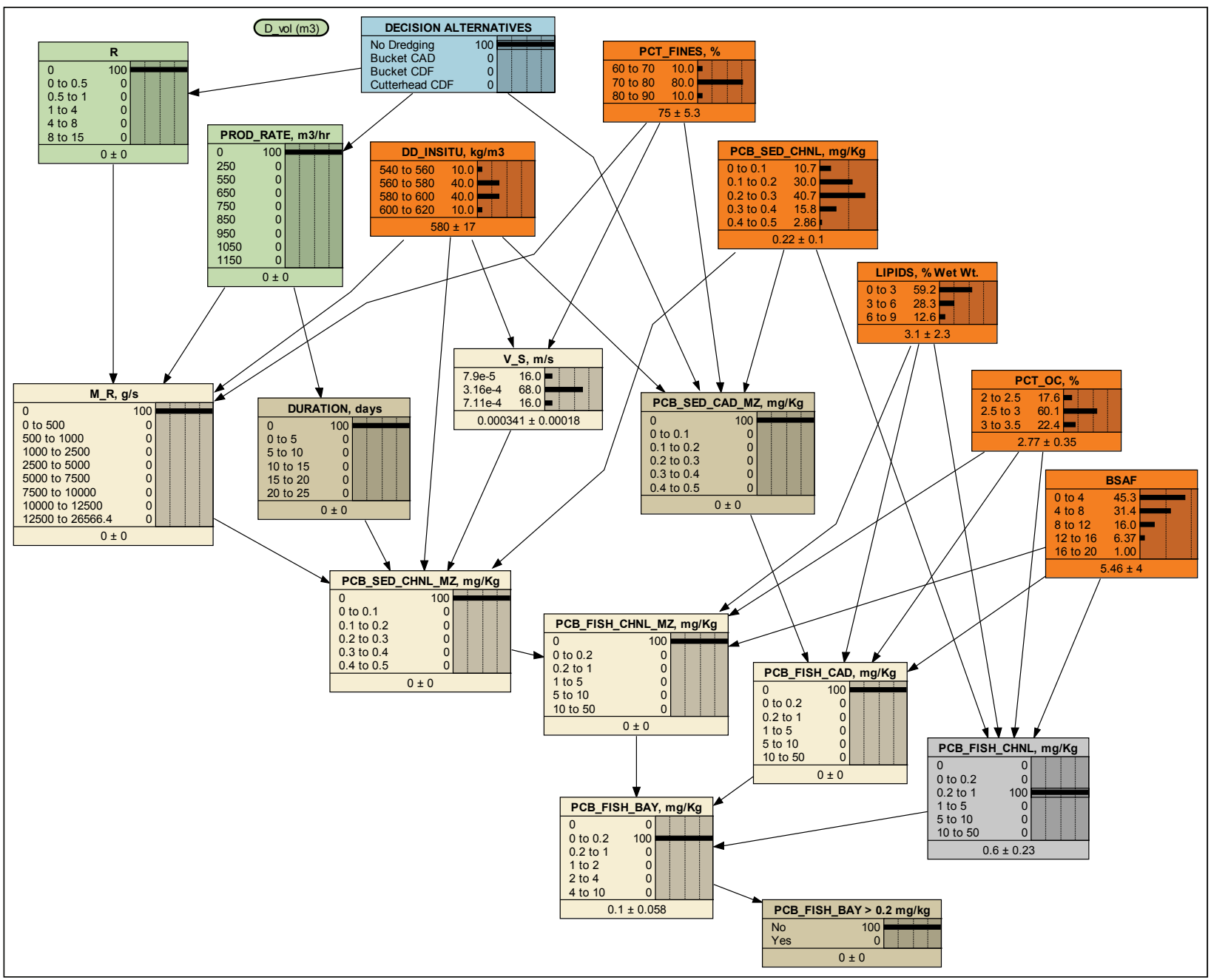

Figure 10. Diagnostic inference with instantiation of the PCB_FISH_BAY node. 
instantiation of the No_Dredging alternative because information is being obtained prior to implementation of a dredging alternative. The prior probabilities are shown in Figure 6. The posterior probabilities, in Figure 10 are obtained using Bayes' rule. Effects of updating can be seen in the PCB_SED_CHNL, LIPIDS, PCT_OC, and BSAF nodes. For example, comparing prior and posterior distributions for BSAF (in Figure 6 and 10, respectively) - hard evidence that the $\mathrm{PCB}$ concentration in fish tissue is between 0.2 and $1 \mathrm{mg} / \mathrm{kg}$ - shifts the probability mass in the BSAF node downward, suggesting that the true value of BSAF in this system may be lower than was previously assumed. A similar effect can be seen in the LIPIDS node. The updated probability mass in the PCT_OC node has shifted upward slightly, to indicate a slight increase in the probability of a higher fraction of organic carbon in sediment. In summary, obtaining information about actual PCB fish tissue concentrations in the channel has enabled the port authority to update the prior probability distributions characterizing uncertainty in site conditions.

\section{Value of Information (VOI) Analysis}

Information can have value at various stages of a technical assessment designed to provide support for an environmental management decision. Scientists and engineers often focus on the uncertainty variance of predicted outcomes from their assessments and estimate how much this variance might be reduced by new or additional data. This approach has been used, for example, by groundwater scientists modeling aquifer water elevations, flow rates, travel times and resulting contaminant plumes, as well the projected effects of remediation alternatives (Massmann and Freeze 1987a,b; Loaiciga et al.1989; Reichard and Evans 1989; Cleveland and Yeh 1990; Cleveland and Yeh 1991; McKinney and Loucks 1992; James and Gorelick 1994; Wagner 1995, 1999; Small, 1997; Sohn et al., 2000). These estimated model outputs are all uncertain as a result of uncertain subsurface conditions; in particular, the spatial profile of soil permeability or hydraulic conductivity in the aquifer, and other physical or geochemical properties of the system. Additional data might be collected to reduce uncertainty by sampling more frequently from existing monitoring wells, drilling additional monitoring wells to characterize the soils and/or groundwater at a higher level of spatial resolution, and analyzing additional chemical constituents in the groundwater. A broader set of laboratory or field studies could also be considered to reduce either site-specific or general scientific uncertainties that affect the basic 
formulation of groundwater models and the accuracy and precision of their predictions.

Similar options for data collection and additional scientific study are available in virtually all environmental and engineering domains where uncertainties in key model assumptions, formulations, inputs and resulting predictions prevail (e.g., Morgan and Henrion, 1990; Patwardhan and Small, 1992; Smith and French, 1993; Brand and Small, 1995; Abbaspour et al., 1996; Chao and Hobbs, 1997; Casman et al., 1999). In general, the uncertainty variance of a variable is a priori expected to decrease as more data are collected. However, additional data can sometimes cause the uncertainty variance to increase. When this occurs, the data is sometimes characterized as a "surprise" that causes scientists to recognize possible processes and futures that they had not previously considered or that had been viewed as very unlikely (Shlyakhter,1994; Morgan and Keith, 1995; Casman et al., 1999; Hammitt and Shlyakhter, 1999).

In addition to improvements in scientific knowledge and associated reductions in the uncertainty variance of technical models and assessments, decision scientists have developed methods for determining the worth of this information for clarifying uncertain decisions (Raiffa, 1968; Keeney, 1982; Winkler and Murphy, 1985; Clemen, 1996; Chao and Hobbs, 1997). The key question regarding scientific uncertainty then becomes: In the context of pending risk management decisions, do these uncertainties matter? To address this question, decision scientists have developed a method for VOI analysis to determine:

1. whether a reduction in the uncertainty might lead the decision maker to choose a different alternative (i.e., alter a decision); and

2. what the expected increase is in the monetary value of the decision as a result of obtaining the new information.

Examples that focus on the sensitivity of the decision are found in Merz et al. (1992), Clark (1997) and Mokhtari and Frey (2005). Examples that focus on the monetary value of information can be found in Dakins, et al. (1994), Costello et al. (1998), Yokota and Thompson (2004a,b), Borisova et al. (2005), Cox et al. (2005), and Bouma et al. (2009).

The decision context in which the uncertainty is assessed is the primary factor in determining which VOI calculations to perform. While monetary VOI calculations are most common in the literature, they are often difficult 
to implement in practice when key attributes of the outcome space are difficult or impossible to monetize, and when more upstream outcomes (such as ambient concentrations or exposure levels) are used as the basis for regulation. In these cases, a VOI analysis can still be performed to determine whether a reduction in uncertainty might lead a decision maker to alter a decision as long as uncertainty as to whether the regulatory limit will be achieved is considered (e.g., the probability with which the standard will be met given the scientific uncertainties in a fate, transport, and exposure model).

\section{Value of Information in the Port Essayons Decision Model}

The following example of VOI analysis is developed using a technical subspace of the Port Essayons dredging decision model. Figure 7 shows the subspace of the network selected for this demonstration of VOI analysis. This subspace of the network predicts the probability of exceeding the critical limit of $0.2 \mathrm{mg} / \mathrm{kg}$ PCB concentration in fish tissue. The lower the probability of exceeding the critical PCB fish tissue concentration, the higher is the assurance that the standard will be met. Low probabilities of exceeding the $0.2 \mathrm{mg} / \mathrm{kg} \mathrm{PCB}$ concentration in fish are thus likely to be sought (e.g., 0.05, 0.10, or 0.20).

In this analysis, the Cutterhead_CDF alternative has been selected a priori. The decision maker must decide whether to implement the Cutterhead_CDF alternative (Dredge) or not to implement the Cutterhead_CDF alternative (Do Not Dredge). The decision rule is that if PCB concentrations in bay fish are below $0.2 \mathrm{mg} / \mathrm{kg}$ with a specified probability, the Dredge alternative will be selected. Otherwise, the Do Not Dredge alternative will be selected. This demonstration of VOI analysis addresses the following question: Would a reduction in the uncertainty associated with SDNs and SCNs alter the decision (Dredge or Do Not Dredge), given that the Cutterhead_CDF alternative has already been selected?

This decision (Dredge or Do Not Dredge) is based on the predicted probability that the critical fish tissue concentration will be met. As shown in the PCB_FISH_BAY $>0.2 \mathrm{mg} / \mathrm{kg}$ node in Figure 11, the Cutterhead_CDF alternative has a 0.151 probability of exceeding the $0.2 \mathrm{mg} / \mathrm{kg}$ standard. Thus, if the critical probability of exceeding the $0.2 \mathrm{mg} / \mathrm{kg}$ standard is greater than 0.151, the Dredge alternative is preferred. If the critical 
probability of exceeding the $0.2 \mathrm{mg} / \mathrm{kg}$ standard is less than 0.151 , then the Do Not Dredge alternative will be selected.

To demonstrate a VOI analysis for uncertain variables, it is necessary to consider how possible reductions in the uncertainty of these variables might lead to a change in the a priori decision. First, a sensitivity analysis is performed to identify the uncertain variables that are likely to be most important in estimating the probability that the regulatory standard for fish tissue PCB concentrations will be exceeded. Following Merz et al. (1992) and Stiber et al. (1999), the potential change in the log-odds (LO) of the probability of exceedance is used as the metric for sensitivity:

$$
\mathrm{LO}=\ln \left(\frac{\text { Prob[PCB_FISH_BAY }>0.2 \mathrm{mg} / \mathrm{kg}]}{1-\text { Prob[PCB_FISH_BAY }>0.2 \mathrm{mg} / \mathrm{kg}]}\right) .
$$

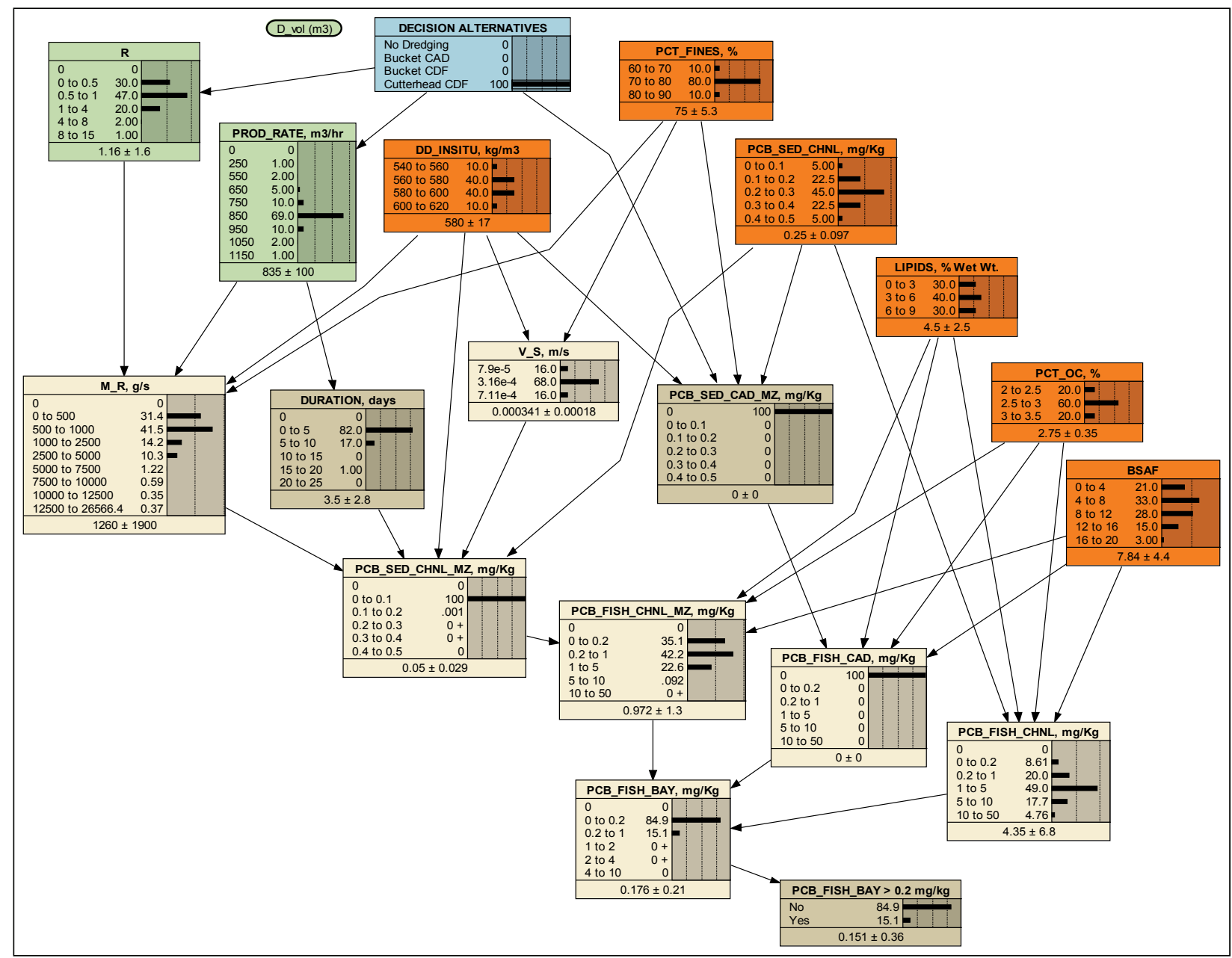

Figure 11. A Bayesian network for the determinants of PCB concentrations in bay fish. The model estimates the probability that fish tissue concentrations will exceed $0.2 \mathrm{mg} / \mathrm{kg}$. The network is shown with prior uncertainties and Cutterhead_CDF is chosen as the dredging alternative. 
Tables 9-11 show results of the analysis for the seven SCNs and SDNs. Table 9 shows the predicted probability that fish tissue PCB concentrations are exceeded if each of the uncertain variables is instantiated one-at-a-time at its lowest and highest possible states. Only instantiation of LIPIDS, PCT_OC, and BSAF have any effect on the probability of exceeding the regulatory standard. Table 10 shows the corresponding effects on the predicted log-odds ratio. Table 11 shows the change in the log-odds ratio for each case. Instantiation of four of the inputs (R, PROD_RATE, PCT_FINES, and DD_INSITU) to their lower- and upper-bound states has virtually no effect on the predicted probabilities or changes in the log-odds of meeting the $0.2 \mathrm{mg} / \mathrm{kg}$ standard (when the prior uncertainty is maintained for the other nodes). BSAF and LIPIDS have significant effects, while a change in PCT_OC has less effect. Therefore, BSAF and LIPIDS are carried forward for further analysis and the other variables are dropped from consideration.

Table 9. Predicted Prob[PCB_FISH_BAY $>0.2 \mathrm{mg} / \mathrm{kg}$ ].

\begin{tabular}{|l|l|l|l|}
\hline \multirow{2}{*}{ Variable } & \multicolumn{3}{|c|}{ Uncertain variable state } \\
\cline { 2 - 4 } & Low & Prior & High \\
\hline R & 0.151 & 0.151 & 0.151 \\
\hline PROD_RATE & 0.151 & 0.151 & 0.151 \\
\hline PCT_FINES & 0.151 & 0.151 & 0.151 \\
\hline DD_INSITU & 0.151 & 0.151 & 0.151 \\
\hline LIPIDS & 0.0105 & 0.151 & 0.305 \\
\hline PCT_OC & 0.197 & 0.151 & 0.112 \\
\hline BSAF & 0.00233 & 0.151 & 0.429 \\
\hline
\end{tabular}

Table 10. Effect on LO(Prob[PCB_FISH_BAY $>0.2 \mathrm{mg} / \mathrm{kg}]$ ).

\begin{tabular}{|l|l|l|l|}
\hline \multirow{2}{*}{ Variable } & \multicolumn{3}{|c|}{ Uncertain variable state } \\
\cline { 2 - 4 } & Low & Prior & High \\
\hline R & -1.72678 & -1.72678 & -1.72678 \\
\hline PROD_RATE & -1.72678 & -1.72678 & -1.72678 \\
\hline PCT_FINES & -1.72678 & -1.72678 & -1.72678 \\
\hline DD_INSITU & -1.72678 & -1.72678 & -1.72678 \\
\hline LIPIDS & -4.54582 & -1.72678 & -0.8236 \\
\hline PCT_OC & -1.40515 & -1.72678 & -2.07047 \\
\hline BSAF & -6.05955 & -1.72678 & -0.28593 \\
\hline
\end{tabular}


Table 11. Change in LO(Prob[PCB_FISH_BAY $>0.2 \mathrm{mg} / \mathrm{kg}]$ ) relative to prior.

\begin{tabular}{|l|l|l|l|}
\hline \multirow{2}{*}{ Variable } & \multicolumn{3}{|c|}{ Uncertain variable state } \\
\cline { 2 - 4 } & Low & Prior & High \\
\hline R & 0 & - & 0 \\
\hline PROD_RATE & 0 & - & 0 \\
\hline PCT_FINES & 0 & - & 0 \\
\hline DD_INSITU & 0 & - & 0 \\
\hline LIPIDS & -2.81905 & - & 0.903179 \\
\hline PCT_OC & 0.321628 & - & -0.34369 \\
\hline BSAF & -4.33277 & - & 1.440847 \\
\hline
\end{tabular}

To demonstrate VOI calculations for LIPIDS and BSAF, a pre-posterior analysis is implemented to determine the probability that a study to obtain perfect information about these variables will lead to a change in the a priori preferred decision: Dredge or Do Not Dredge. The analysis is performed for different probabilities of meeting the critical PCB fish tissue concentration, since this probability determines whether a Dredge or Do Not Dredge decision is made before undertaking the study. If the allowable probability of exceeding the $0.2 \mathrm{mg} / \mathrm{kg}$ standard is above 0.151 under the prior knowledge state, then the baseline decision is to Dredge. If the allowable probability of meeting the standard is below 0.151 under the prior knowledge state, the baseline decision is Do Not Dredge. The steps in the pre-posterior analysis are as follows:

1. Identify the decision alternative that is preferred a priori (Dredge or Do Not Dredge).

2. The uncertain variables of interest (LIPIDS or BSAF) are instantiated to their possible states one at a time. For each case, it is noted whether doing so results in a switch in the decision (Dredge or Do Not Dredge). The decision switches from Dredge to Do Not Dredge when instantiation causes Prob[PCB_FISH_BAY > $0.2 \mathrm{mg} / \mathrm{kg}$ ] to increase above the critical probability (when a priori it was below). The decision switches from Do Not Dredge to Dredge when fixing the parameter value causes the predicted Prob[PCB_FISH_BAY > $0.2 \mathrm{mg} / \mathrm{kg}$ ] to decrease below the critical probability (when a priori it was above).

3. The probability that a switch in decision preference occurs is then determined as the probability-weighted fraction of cases (with the variable fixed to one of its possible states) in which a switch occurs. The 
probabilities used in the weighting are the a priori probabilities assigned to each uncertain variable state, shown in Figure 7. That is, before conducting the study, we do not know what the results will be; however, the probability of each result (assuming perfect information) must be equal to our assigned prior probability for each uncertain variable state. When estimating the value of imperfect information, studies are represented by assigning different probabilities to each study outcome, conditioned on the true state of the uncertain variable.

The results of the VOI analysis for LIPIDS and BSAF are summarized in Figures 12 and 13, respectively. The $x$-axis is the critical maximum allowable probability of exceeding the fish tissue concentration standard. The $y$-axis (Dredge $(\mathrm{No}=\mathrm{o}, \mathrm{Yes}=1)$ ) is synonymous with the probability of switching the decision. These figures show that LIPIDS and BSAF must be at their lowest levels (LIPIDS 0-3\%, BSAF 0-4) to satisfy a decision rule that requires the probability of exceeding the critical $\mathrm{PCB}$ concentration in fish tissue to be less than 0.05. As the decision rule is relaxed (e.g., the critical probability is increased), the Dredge alternative is preferred under increasingly higher-level states. The highest states of the LIPIDS and BSAF nodes preclude dredging until the critical allowable probability of exceeding $0.2 \mathrm{mg} / \mathrm{kg}$ reaches 0.4 in the case of LIPIDS, and 0.5 in the case of BSAF. The information value, represented by the probability that a switch in preference relative to the prior preference will occur (black solid line in each figure) is highest when the critical probability for the decision rule is close to the prior projected probability of exceeding $0.2 \mathrm{mg} / \mathrm{kg}$ ( $=0.151$ in this case). As such, both curves peak when the critical probability in the decision rule is at or about 0.15 . When compliance with a regulatory limit is projected to occur (or not to occur) by only a small amount, and uncertainty is considered, it is not surprising that it will be important to collect more information to reduce the attendant uncertainty. 


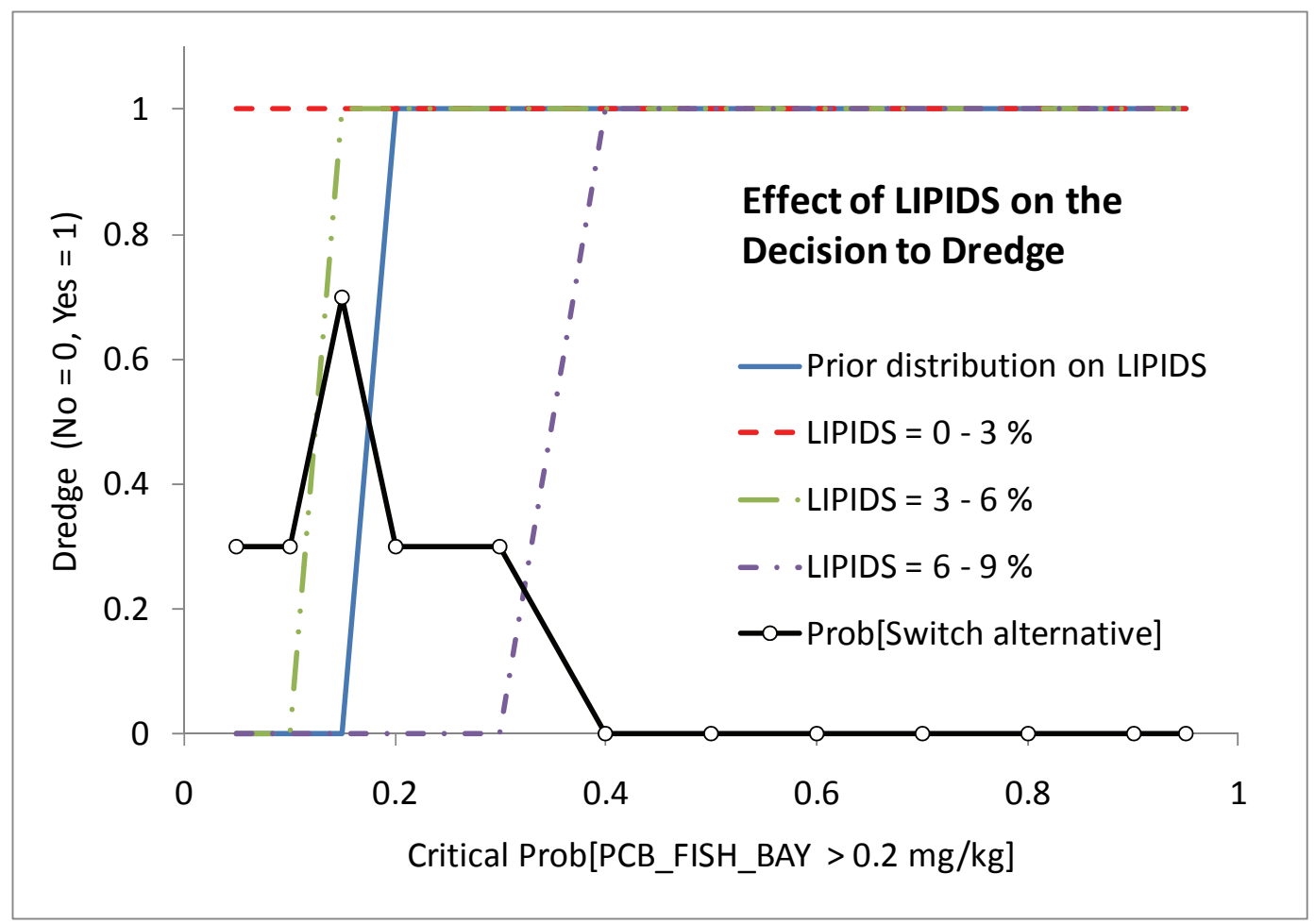

Figure 12. VOI analysis for LIPIDS. The black line (with solid white circles) shows the probability that a perfect study will cause the preferred decision alternative to switch. Also shown are the preferred decision alternative $(0=$ Do Not Dredge; $1=$ Dredge $)$ under the prior uncertainty (solid blue line) and with fixed values of the LIPIDS (dashed lines) as a function of the allowable projected probability that PCBs in bay fish will be $>0.2 \mathrm{mg} / \mathrm{kg}$. 


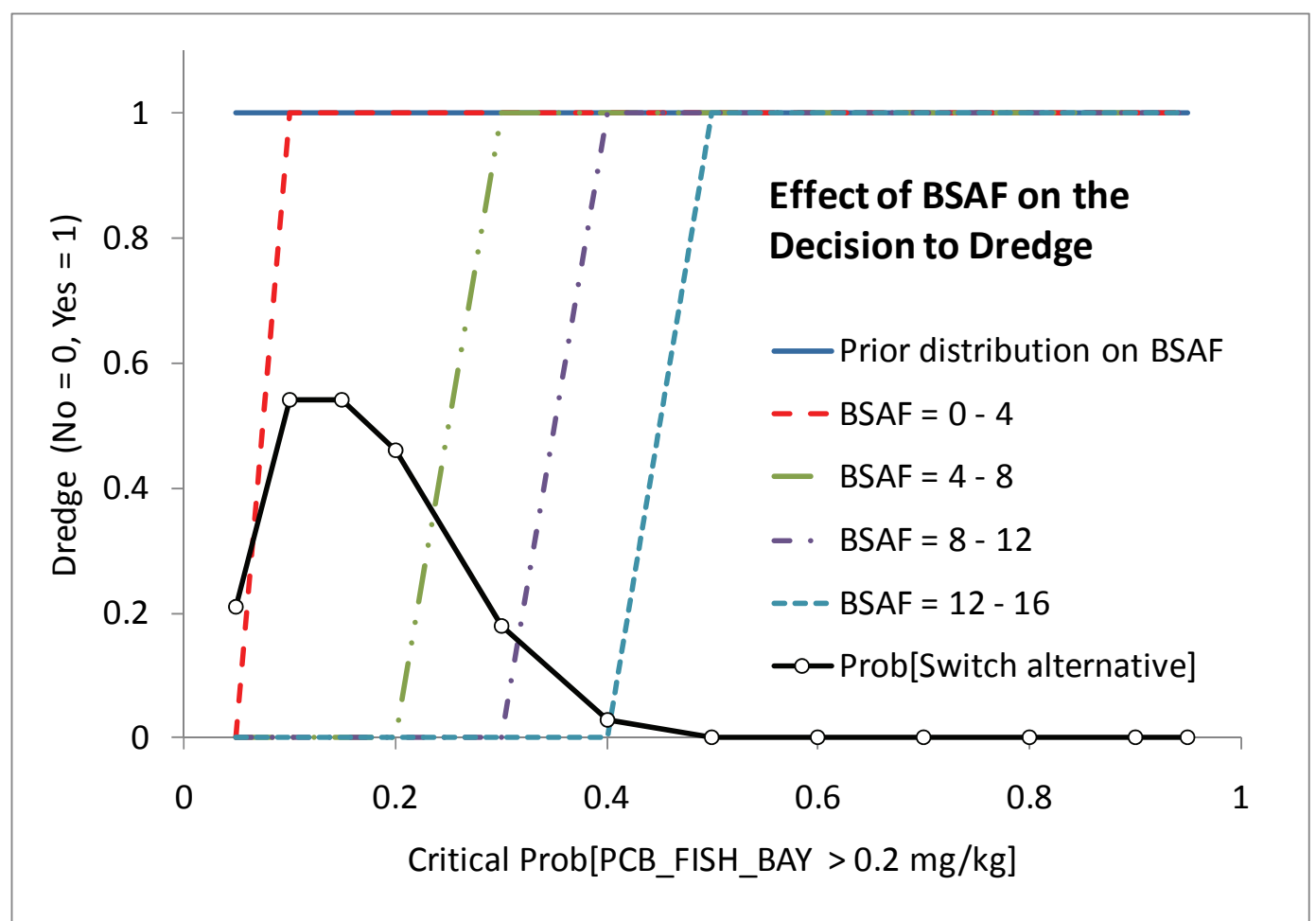

Figure 13. VOI analysis for BSAF. The black line (with solid white circles) shows the probability that a perfect study will cause the preferred decision alternative to switch. Also shown are the preferred decision alternative $(0=$ Do Not Dredge; $1=$ Dredge $)$ under the prior uncertainty (solid blue line) and with fixed values of the BSAF (dashed lines) as a function of the allowable projected probability that PCBs in bay fish will be $>0.2 \mathrm{mg} / \mathrm{kg}$. 


\section{Conclusions}

Bayesian networks are highly efficient representations of joint probability distributions; and any joint probability distribution can be represented using a DAG (Pourret, O., 2008). At least in theory, probabilistic networks provide the capability to solve very complex inference problems involving hundreds and even thousands of variables. They are especially useful in situations when there are dependencies among a large number of uncertainties (Bromley et al. 2005). Instead of pursuing a detailed model of small-scale processes, the focus is on compiling available information in its various forms and using that information to improve the level of understanding about large, complicated management problems in the context of causes and effects in the system (Sadoddin et al. 2005).

Bayesian networks are useful for rapid scoping and for intuitive presentation of ecological relationships (McCann Marcot and Ellis 2006). This is due to the graphical way in which problems are structured and the interactive representation of decision problems. Thus, they can provide a focal point for engaging stakeholders in analysis and decision making. When multiple stakeholders participate in structuring the network, the networks promote a shared understanding of the system being managed and stimulate a rigorous examination of decision alternatives (Nyberg, Marcot and Sulyma 2006). This makes them ideal tools for communicating and interacting with stakeholders.

When environmental issues are complex, system dynamics are poorly understood and there are large numbers of uncertainties present. Bayesian networks enable model developers to break down complex problems into relatively simple components and address each component separately in relation to parent nodes. As new information becomes available, individual nodes can be later updated or adapted without disturbing other parts of the network (Sadoddin 2005). Because of the relative simplicity with which information can be updated in Bayesian network applications, they are ideal for implementation of adaptive management practices (Nyberg Marcot and Sulyma 2006). Adaptive management involves structuring a decision or problem given what is known at the time, implementing a set of experiments to obtain new information, and then reevaluating the decision when new information becomes available. 
Bayesian networks provide a means to integrate the results of separate modeling efforts that may be undertaken to support a decision. For example, in the context of dredging decision support, this might include the integration of hydrodynamic models, fate and transport models, and food web models to characterize ecological impacts of sediment resuspension in an estuary. Because there is no transference of mass or flow among nodes in a Bayesian network, there are few limitations in how system variables are represented, making it possible to ignore discrepancies in scale or units of analysis used in supporting models (Borsuk et al. 2011). A related advantage is the ability to use both quantitative and qualitative variables in an analysis; however, qualitative variables must be well-specified (i.e., unambiguous).

The probabilistic approach is ideal in limited information environments, providing an appropriate way of dealing with incomplete information and missing data. Conditional probabilities can be derived from data, model outputs, or engineering judgment. Algorithms to derive probabilities from data can be employed using large or small datasets; the algorithms can function with missing data. While it is best to rely on objective information as much as possible, it is common to encounter situations in which there is a lack of knowledge about important components of an environmental system or process or in which data about the system of interest is not available (Pollino et al. 2007b). In such cases, Bayesian networks offer a structured approach for integrating objective and subjective knowledge into a single representation of the system. In so doing, the approach forces the decision maker to structure his beliefs using mathematical formalisms that help ensure proper reasoning about uncertainty. If subjective knowledge is used to structure and parameterize a decision model in the initial stages of modeling, it is usually the goal to improve understanding of the decision problem, identify information needs, and eventually replace or update subjective information with objective information as that information becomes available.

While there are many advantages to using Bayesian networks, the literature describes many challenges to their implementation as well. An important limitation of Bayesian networks is their directed acyclic structure, which limits the description of relationships among nodes to one-way cause and effect. This prevents the representation of feedback relationships that may be known to exist in some systems (Uusitalo 2007, Barton et al. 2008). It is also very difficult to represent temporal dynamics 
in Bayesian networks, although methods exist for doing so (McCann Marcot and Ellis 2006, Uusitalo 2007). In discrete Bayesian networks, continuous variables must be discretized. The benefits of discretization are that it simplifies expert elicitation, acknowledges that the understanding of many parameters and relationships in a model (and the data available to support the description of those relationships) may be rudimentary, and facilitates statistical inference (Pollino et al. 2007b). However, discretization is often a subjective process. It can introduce additional uncertainty into the analysis (Borsuk 2010) and may lead to oversimplification of a problem (Nyberg Marcot and Sulyma 2006). Modeling results are often found to be sensitive to the way that variables are discretized and to the levels of resolution used in discretization (Barton et al. 2008). Borsuk et al. (2011) say that discretization may tend to introduce vagueness or ambiguity, leading to difficulties when eliciting probabilities from multiple experts who may have different interpretations about the meaning of a node or difficulties in interpreting model results. Generally, this can be avoided by using well-defined nodes with careful definitions and unambiguous states.

Conditional probabilities can be difficult to obtain (McCann, Marcot, and Ellis 2006 p. 3059). The ideal situation exists when all probabilities can be obtained from data. However, rare events may tend to be underrepresented in databases, leading to biased distributions of probabilities. In many cases, it may be very difficult to obtain data for some nodes. In such cases, probabilities must be obtained from models or through expert elicitation. However, many authors report that experts are often reluctant to provide probabilities. Experts may also tend to make poor probability estimates (Pike 2004), a trait that seems to arise from overconfidence (Uusitalo 2007) or the use of heuristics (Morgan and Henrion 1990). For nodes with many parents (e.g., more than three or four), CPTs can become quite complex, which also does not help overcome any reluctance on the part of experts to provide probabilities. Marcot (2006a) provides guidelines on how to structure Bayesian networks to keep CPTs tractable (McCann, Marcot, and Ellis 2006).

There are many advantages to using Bayesian networks. Project conditions that might motivate the use of Bayesian networks as a decision modeling approach include the need for a coherent and mathematically sound handling of uncertainty, an intuitive and compact representation of cause and effect relationships, a representation of dependence and conditional 
independence relationships, and diagnostic statistical inference (Kjaerulff and Madsen 2008). Other project conditions that might motivate the use of Bayesian networks include:

- The decision problem transcends multiple disciplines, and information or models originating from multiple disciplines must be integrated into one common representation of a system.

- The system being represented is complex, and multiple models that are functionally incompatible must be integrated to represent the system.

- Objective and subjective knowledge must be integrated, or engineering judgment is being incorporated into the decision making process.

- One has data about conditions within a system, but the level of understanding is insufficient to explain the relationships among the observable quantities in the system.

- A recurring decision will be updated as new information emerges (adaptive management).

It is important to recognize when Bayesian networks might not always be the best approach to modeling a problem. For example, Bayesian networks should not be used when processes can be fully explained mechanistically using first order principles. They should not be used as a substitute for mechanistic models, when the problem is restricted to one discipline, the variables and events of the problem domain cannot be well-defined, or when there is no uncertainty. However, none of these conditions usually apply to most dredging decisions. 


\section{References}

Abbaspour, K. C., R. Schulin, R. E. Schlappi, and H. Fluhler. 1996. A Bayesian approach for incorporating uncertainty and data worth in environmental projects. Environmental Modeling and Assessment 1: 151-158.

Adriaenssens, V., P. L. M. Goethals, J. Charles, and N. De Pauw. 2004. Application of Bayesian belief networks for the prediction of macro-invertebrate taxa in rivers. Annales de Limnologie - International Journal of Limnology 40(3): 181191.

Ames, D. P., B. T. Neilson, D. K. Stevens, and U. Lall. 2005. Using Bayesian networks to model watershed management decisions: An East Canyon Creek case study. Journal of hydroinformatics 7: 267-282.

Amstrup, S. C., B. G. Marcot, and D. C. Douglas. 2008. A Bayesian network modeling approach to forecasting the $21^{\text {st }}$ century worldwide status of polar bears. In Arctic Sea Ice Decline: Observations, Projections, Mechanisms, and Implications, Geophysical Monograph 18o, ed. E.T. DeWeaver, C.M. Bitz, and L.B. Tremblay, 213-268. Washington, DC: American Geophysical Union.

Bacon, P. J., J. D. Cain, and D. C. Howard. 2002. Belief network models in land manager decisions and land use change. Journal of Environmental Management 65(1): 123 .

Barton, D. N., T. Saloranta, S. J. Moe, H. O. Eggestad, and S. Kuikka. 2008. Bayesian belief networks as a meta-modelling tool in integrated river basin management Pros and cons in evaluating nutrient abatement decisions under uncertainty in a Norwegian river basin. Ecological Economics 66(1): 91-104.

Borisova, T, J. Shortle, R. D. Horan, and D. Abler 2005. Value of information for water quality management. Water Resources Research, 41(1): 1-11.

Borsuk, M. E. 2004. Predictive assessment of fish health and fish kills in the Neuse River estuary using elicited engineering judgment. Human and Ecological Risk Assessment 10(2): 415-434.

Borsuk, M. E., S. Schweizer, and P. Reichert. 2011. A probability network model for integrative river rehabilitation, planning, and management. Integrated Environmental Assessment and Management in press.

Borsuk, M. E., C. A. Stow, and K. H. Reckhow. 2004. A Bayesian network of eutrophication models for synthesis, prediction and uncertainty analysis. Ecological Modelling 173: 219-239.

Borsuk, M. E., P. Reichert, A. Peter, E. Schager, and P. Burkhardt-Holm. 2006. Assessing the decline of brown trout (Salmo trutta) in Swiss rivers using a Bayesian probability network. Ecological Modelling 192(1-2): 224-244. 
Bouma, J. A., H. van der Woerd, and O. Kuik, 2009. Assessing the value of information for water quality management in the North Sea. Journal of Environmental Management 90(2): 1280-1288.

Brand, K. P., and M. J. Small.1995. Updating uncertainty in an integrated risk assessment: Conceptual framework and methods. Risk Analysis 15(6): 719-731.

Bray, R. N. 2008. Environmental Aspects of Dredging. Leiden, The Netherlands: Taylor and Francis.

Bromley, J., N. A. Jackson, O. J. Clymer, A. M. Giacomello, and F. V. Jensen. 2005. The use of Hugin to develop Bayesian networks as an aid to integrated water resource planning. Environmental Modelling \& Software 20(2): 231-242.

Burgman, M. A., B. A. Wintle, C. A. Thompson, A. Moilanen, M. C. Runge, and Y. BenHaim. 2010. Reconciling uncertain costs and benefits of Bayes nets for invasive species management. Risk Analysis 30(2): 277-284.

Casman, E. A., M. G. Morgan, and H. Dowlatabadi, 1999. Mixed levels of uncertainty in complex policy models. Risk Analysis 19(1): 33-42.

Chao, P. T., and B. F. Hobbs. 1997. Decision analysis of shoreline protection under climate change uncertainty. Water Resources Research 33(4): 817-830.

Clark, D. 1997. Computational methods for probabilistic decision trees. Comput Biomed Res. 30(1):19-33.

Clarke, D. G., M. R. Palermo, and T. C. Sturgis. 2001. Subaqueous cap design: Selection of bioturbation profiles, depths, and rates. DOER Technical Notes Collection ERDC TN-DOER-C21. Vicksburg, MS: U.S. Army Engineer Research and Development Center http://el.erdc.usace.army.mil/elpubs/pdf/doerc21.pdf.

Clemen, R. T. 1996. Making Hard Decisions: An Introduction to Decision Analysis (2nd ed.). Belmont, CA: Duxbury Press.

Cleveland, T., and W. W.-G. Yeh. 1990. Sampling network design for transport parameter identification. Journal Water Resources Planning \& Management 116(6): 765783 .

Cleveland, T., and W. W.-G. Yeh. 1991. Optimal configuration and scheduling of groundwater tracer test. Journal Water Resources Planning \& Management 117(1): 37-51.

Costello C. J., R. M. Adams, and S. Polasky. 1998. The value of El Niño forecasts in the management of salmon: A stochastic dynamic assessment. Am J Agric Econ $80(4): 765-777$.

Cox, Jr., Luis A., D. A. Popken, J. J. Van Sickle, and R. Sahu. 2005. Optimal tracking and testing of U.S. and Canadian herds for BSE: A Value-of-Information (VOI) approach. Risk Analysis 25(4): 827-840.

Dakins, M. E., J. E. Toll, and M. J. Small. 1994. Risk-based environmental remediation: Decision framework and role of uncertainty. Environmental Toxicology \& Chemistry 13(12): 1907-1915. 
Darwiche, A. 2009. Modeling and reasoning with Bayesian networks. New York, NY: Cambridge University Press.

Gibbs, M. T. 2007. Assessing the risk of an aquaculture development on shorebirds using a Bayesian belief model. Human and Ecological Risk Assessment: An International Journal 13(1): 156-179.

Hammitt, J. K., and A. I. Shlyakhter. 1999. The expected value of information and the probability of surprise. Risk Analysis 19(1): 135-152.

James, B. R., and S. M. Gorelick. 1994. When enough is enough: The worth of monitoring data in aquifer remediation and design. Water Resources Research 30(12): 34993513 .

Hayes, D. F., T. D. Borrowman, and P. R. Schroeder. 2007. Process-based estimation of sediment resuspension losses during bucket dredging. Proceedings of the World Dredging Congress XVIII Annual Dredging Seminar. Orlando, FL. May 27-June $1,2007$.

Hayes, D. F., and C. H. Je. 200o. DREDGE Model User's Guide. US Army Engineer Research and Development Center, Dredging Operations and Technical Support Program, http://el.erdc.usace.army.mil/elmodels/pdf/dredge.pdf.

Hayes, D. F., and P. R. Schroeder. 1992. Documentation of the SETTLE Module of ADDAMS: Design of confined disposal facilities for solids retention and initial storage. Technical Note EEDP 06-18. Vicksburg, MS: U.S. Army Engineer Research and Development Center.

Herbich, J. B. 2000. Handbook of dredging engineering (non-standard page numbers). New York, NY: The McGraw Hill Companies.

Howard, R. A., and J. E. Matheson. 1984. Readings in the principles and practice of decision analysis. Menlo Park, CA: Strategic Decision Systems.

Howard, R. A. 1966. Decision analysis: Applied decision theory. In Proceedings of the Fourth International Conference on Operational Research 55-71. New York: Wiley Interscience.

Jensen, F. V., S. L. Lauritzen, and K. G. Olesen. 1990. Bayesian updating in causal probabilistic networks by local computations. Computational Statistics Quarterly 4: 269-282.

Keeney, R. L. 1982. Decision analysis: An overview. Operations Research 30(5): 803838.

Kjaerulff, U. B., and A. L. Madsen. 2008. Bayesian networks and influence diagrams: A guide to construction and analysis. New York, NY: Springer Science and Business Media.

Kwon, T. D., S. W. Fisher, G. W. Kim, H. Hwang, and J. E. Kim. 2007. Trophic transfer and biotransformation of polychlorinated biphyenyls in zebra mussel, round goby, and smallmouth bass in Lake Erie, USA. Environmental Toxicology and Chemistry 25(4): 1068-1078. 
Koller, D., and N. Friedman. 2009. Probabilistic graphical models: Principles and techniques. Cambridge, MA: MIT Press.

Kragt, M. E., L. T. H. Newham, and A. J. Jakeman. 2009. A Bayesian network approach to integrating economic and biophysical modeling. In Proceedings of the $18^{\text {th }}$ World IMACS / MODSIM Congress, 13-17 July 2009, 2377-2383. Cairns, Australia.

Kuikka, S., M. Hilden, H. Gislason, S. Hansson, H. Sparholt, and O. Varis. 1999. Modeling environmentally driven uncertainties in Baltic cod (Gadus morhua) management by Bayesian influence diagrams. Canadian Journal of Fisheries and Aquatic Science 56(4): 629-641.

Lauritzen, S. L., and D. J. Spigelhalter. 1988. Local computations with probabilities on graphical structures and their application to expert systems. Journal of the Royal Statistical Society, Series B 50(2): 157-224.

Lee, D. C., and B. E. Rieman. 1997. Population viability assessment of salmonids using probabilistic networks. North American Journal of Fisheries Management 17(4): $1144-1157$.

Loaiciga, H., A., R. J. Charbeneau, L. G. Everett, G. E. Fogg, B. F. Hobbs, S. Rouhani. 1992. Review of Ground-Water Quality Monitoring Network Design. Journal of Hydraulic Engineering 118(1), 11-37

MacDonald, C. R., C. D. Metcalfe, G. C. Balch, and T. L. Metcalfe. 1993. Distribution of PCB congeners in seven lake systems: Interactions between sediment and food web transport. Environmental Toxicology and Chemistry 12(11): 1991-2003.

Marcot, B. 2006a. Characterizing species at risk 1: Modeling rare species under the Northwest Forest Plan. Ecology and Society 11(2):10 URL: http://www.ecologyandsociety.org/vol11/iss2/art10/

Marcot, B. G. 2006b. Characterizing species at risk II: Using Bayesian belief networks as decision support tools to determine species conservation categories under the Northwest Forest Plan. Ecology and Society 11(2):12.

Marcot, B. G., J. D. Steventon, G. D. Sutherland, and R. K. McCann. 2006. Guidelines for developing and updating Bayesian belief networks applied to ecological modeling and conservation. Canadian Journal of Forest Research 36(2006): 3063-3074.

Massmann, J., and R. A. Freeze. 1987a. Groundwater contamination from waste management sites: The interaction between risk-based engineering design and regulatory policy, 1. Methodology. Water Resources Research 23: 368-380.

Massmann, J., and R. A. Freeze. 1987b. Groundwater contamination from waste management sites: The interaction between risk-based engineering design and regulatory policy, 2. Results. Water Resources Research 23: 368-380.

McKinney, D. C., D. P. Loucks, 1992. Network design for predicting groundwater contamination. Water Resources Research 28 (1): 133-147. 
McCann, R. K., B. G. Marcot, and R. Ellis. 2006. Bayesian belief networks: Applications in ecology and natural resource management. Canadian Journal of Forest Research 36(12): 3053-3062.

McNay, R. S., B. G. Marcot, V. Brumovsky, and R. Ellis. 2006. A Bayesian approach to evaluating habitat for woodland caribou in north-central British Columbia. Canadian Journal of Forest Research 36: 3117-3133.

Merz, J., M. J. Small, and P. Fischbeck. 1992. Measuring decision sensitivity: A combined Monte Carlo-logistic regression approach. Medical Decision Making 12(2): 189196.

Mokhtari A., and H. C. Frey. 2005. Recommended practice regarding selection of sensitivity analysis methods applied to microbial food safety process risk models. Human and Ecological Risk Assessment 11(3): 591-605.

Morgan, M. G., and D. W. Keith. 1995. Climate-change-Subjective judgments by climate experts. Environ. Sci. Technol. 29(10): A468-A476.

Morgan M. G., and M. Henrion. 1990. Uncertainty: A guide to dealing with uncertainty in quantitative risk and policy analysis. Cambridge UK: Cambridge University Press

Newcombe, C. P., and D. D. MacDonald. 1991. Effects of suspended sediments on aquatic ecosystems. North American Journal of Fisheries Management 11(1): 72-82

Newcombe, C. P., and J. O. T. Jensen. 1996. Channel suspended sediment and fisheries: A synthesis for quantitative assessment of risk and impact. North American Journal of Fisheries Management 16(4): 693-719.

Newman, M. C., Y. Zhao, J. F. Carriger. 2007. Coastal and estuarine ecological risk assessment: The need for a more formal approach to stressor identification. Hydrobiologia 577(1):31-40.

Nyberg, J. B., B. G. Marcot, and R. Sulyma. 2006. Using Bayesian belief networks in adaptive management. Canadian Journal of Forest Research 36(12): 3104-3116

Patwardhan, A., M. J. Small. 1992. Bayesian methods for model uncertainty analysis with application to future sea level rise. Risk Analysis 12(4): 513-523.

Pearl, J. 1988. Probabilistic reasoning in intelligent systems. San Francisco, CA: Morgan Kauffman Publishers, Inc.

Petersen, D. P., B. E. Rieman, J. B. Dunham, K. D. Fausch, and M. K. Young. 2008. Analysis of trade-offs between threats of invasion by nonnative brook trout (Salvelinus fontinalis) and intentional isolation for native westslope cutthroat trough (Oncorhynchus clarkii lewisi). Canadian Journal of Fisheries and Aquatic Sciences 65(4): 557-573.

PIANC The World Association for Waterborne Infrastructure (PIANC). 2009. Dredging Management Practices for the Environment: A Structured Selection Approach, Environmental Commission Report \#100, Brussels, Belgium. 
Pike, W. A. 2004. Modeling drinking water quality violations with Bayesian networks. Journal of the American Water Resources Association 40(6):1563-1578.

Pollino, C. A., A. K. White, B. T. Hart. 2007a. Examination of conflicts and improved strategies for the management of an endangered Eucalypt species using Bayesian networks. Ecological Modelling 201(1):37-59.

Pollino, C. A., O. Woodberry, A. Nicholson, K. Korb, and B. T. Hart. 2007b. Parameterization and evaluation of a Bayesian network for use in an ecological risk assessment. Environmental Modelling and Software 22(8): 1140-1152.

Pourret, O. 2008. Introduction to Bayesian networks. In Bayesian networks: A practical guide to applications, ed. Pourret, O., Naime, P., and Marcot, B. West Sussex, England: John Wiley and Sons Ltd.

Raiffa, H. 1968. Decision analysis: Introductory lectures on choice under uncertainty. Reading, MA: Addison-Wesley.

Reckhow, K. 1999. Water quality prediction and probability network models. Canadian Journal of Fisheries and Aquatic Sciences 56(7):1150-1158.

Reichard, E. G., and Evans, J. S. 1989. Assessing the value of hydrogeologic information for risk-based remedial action decisions. Water Resources Research 25(7): 14511460

Reine, K. J., D. D. Dickerson, and D. G. Clarke. 1998. Environmental windows associated with dredging operations. DOER Technical Notes Collection. TN DOER-E2. Vicksburg, MS: US Army Engineer Research and Development Center.

Sadoddin, A., R. A. Letcher, A. J. Jakeman, L. T. H. Newham. 2005. A Bayesian decision network approach for assessing the ecological impacts of salinity management. Mathematics and Computers in Simulation 69(1-2): 162-176.

Schultz, M. T., K. N. Mitchell, B. K. Harper, and T. S. Bridges. 2010. Decision making under uncertainty. ERDC TR-10-12. Vicksburg, MS: U.S. Army Corps of Engineers.

Seoane, J., J. Bustamante, and R. Diaz-Delgado. 2005. Effect of expert opinion on the predictive ability of environmental models of bird distribution. Conservation Biology 19(2): 512-522.

Shepard, B. B., B. Sanborn, L. Ulmer, D. C. Lee. 1997. Status and risks of extinction for westslope cutthroat trout in the upper Missouri River Basin, Montana. North American journal of fisheries management 17(4):1158-1172.

Shlyakhter, A. I. 1994. An improved framework for uncertainty analysis: Accounting for unsuspected errors. Risk Analysis 14(4): 441-447.

Small, M. J. 1997. Groundwater detection monitoring using combined information from multiple constituents. Water Resources Research 33(5): 957-969.

Smith, C. S., A. L. Howes, B. Price, C. A. McAlpine. 2007. Using a Bayesian belief network to predict suitable habitat of an endangered mammal - The Julia Creek dunnart (Sminthopsis douglasi). Biological Conservation 139(3-4):333-347. 
Smith, J. Q., and S. French, 1993. Bayesian updating of atmospheric dispersion models for use after an accidental release of radiation. The Statistician 42(5), 501-511.

Sohn, M. D., M. J. Small, and M. Pantazidou, 2000. Reducing uncertainty in groundwater site characterization using Bayes Monte Carlo methods. Journal of Environmental Engineering 126(10): 893-902.

Stewart-Koster, B. S., S. E. Bunn, S. J. Mackay, N. L. Poff, R. J. Naiman, and P. S. Lake. 2010. The use of Bayesian networks to guide investments in flow and catchment restoration for impaired river ecosystems. Freshwater Biology 55 (1): 243-260.

Stiber, N. A., M. Pantazidou, and M. J. Small 1999. Expert System Methodology for Evaluating Reductive Dechlorination at TCE Sites. Environmental Science and Technology 33(17):3012-3020.

Suedel, B. C., J. Kim, D. G. Clarke, and I. Linkov. 2008. A risk-informed decision framework for setting environmental windows for dredging projects. Science of the Total Environment 403(1-3):1-11.

Ticehurst, J. L., R. A. Letcher, and D. Rissik. 2008. Integration modelling and decision support: A case study of the Coastal Lake Assessment and Management (CLAM) Tool. Mathematics and Computers in Simulation 78(2-3): 435-449.

Ticehurst, J. L., L. T. H. Newham, D. Rissik, R. A. Letcher, and A. J. Jakeman. 2007. A Bayesian nework approach for assessing the sustainability of coastal lakes in New South Wales, Australia. Environmental Modelling and Software 22(8): 11291139.

US Environmental Protection Agency (USEPA). 2000. Guidance for assessing chemical contaminant data for use in fish advisories: Volume 2: Risk assessment and fish consumption limits, third edition. EPA 823-B-00-008. Washington DC: Office of Water.

US Environmental Protection Agency and US Army Corps of Engineers (USEPA, USACE). 1998. Evaluation of dredged material proposed for discharge in waters of the United States: Inland testing manual-Appendix C, evaluation of mixing. EPA 823-B-98-004. Washington DC: US Environmental Protection Agency Office of Water.

US Army Corps of Engineers (USACE). Dredged material physical properties database. (in preparation) Vicksburg, MS: Engineer Research and Development Center.

Uusitalo, L. 2007. Advantages and challenges of Bayesian networks in environmental modeling. Ecological Modelling 203(3-4):312-318.

von Neumann, J., and O. Morgenstern. 1947. The theory of games and economic behavior. Princeton, NJ: Princeton University Press.

von Winterfeldt, D., and W. Edwards. 2007. Defining a decision analytic structure, Chapter 6 in Advances in decision analysis, ed. W. Edwards, R.F. Miles, and D. von Winterfeldt, 621. Cambridge, UK: Cambridge University Press.

Wagner, B. J. 1995. Recent advances in simulation optimization ground water management modeling. Reviews in Geophysics 33(Suppl. Part 2): 1021-1028. 
Wagner, B. J. 1999. Evaluating data worth for ground-water management under uncertainty. Journal of Water Resources Planning and Management 125(5): 281-288.

Wilber, D. H., and D. G. Clarke. 2001. Biological effects of suspended sediments: A review of suspended sediment impacts on fish and shellfish with relation to dredging activities in estuaries. North American Journal of Fisheries Management 21(3): $855-875$.

Winkler, R. L., and A. H. Murphy.1985. Decision analysis. In Probability, Statistics, and Decision Making in the Atmospheric Sciences, ed. A.H. Murphy and R.W. Katz, 493-524. Boulder, CO: Westview Press.

Wilson, A. G., and A. V. Huzurbazar. 2007. Bayesian networks for multilevel system reliability. Reliability Engineering and System Safety 92(10):1413-1420.

Yokota, F., and K. M. Thompson.2004a. The value of information in environmental health risk management decisions: Past, present, and future. Risk Analysis 24(3): 635-650.

Yokota, F., and K. M. Thompson. 2004b. Value of information literature analysis: A review of applications in health risk management. Medical Decision Making 24(3): 287-298. 


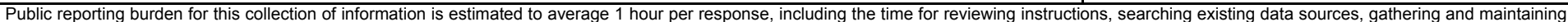

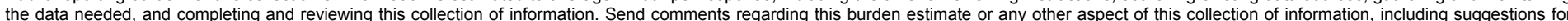

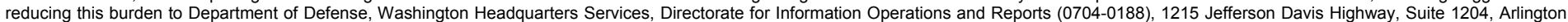

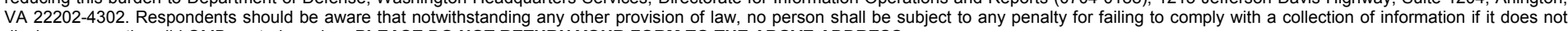
display a currently valid OMB control number. PLEASE DO NOT RETURN YOUR FORM TO THE ABOVE ADDRESS.

\begin{tabular}{l|l} 
1. REPORT DATE (DD-MM-YYYY) & $\begin{array}{c}\text { 2. REPORT TYPE } \\
\text { October } 2011\end{array}$ \\
\hline
\end{tabular}

\section{TITLE AND SUBTITLE}

Bayesian Networks for Modeling Dredging Decisions

\section{AUTHOR(S)}

Martin T. Schultz, Thomas D. Borrowman, and Mitchell J. Small

\section{DATES COVERED (From - To)}

5a. CONTRACT NUMBER

5b. GRANT NUMBER

5c. PROGRAM ELEMENT NUMBER

5d. PROJECT NUMBER

5e. TASK NUMBER

5f. WORK UNIT NUMBER

8. PERFORMING ORGANIZATION REPORT NUMBER

ERDC/EL TR-11-14

Environmental Laboratory

U.S. Army Engineer Research and Development Center

3909 Halls Ferry Road, Vicksburg MS 39180;

Department of Civil and Environmental Engineering and

Department of Engineering and Public Policy

Carnegie Mellon University

5000 Forbes Avenue, Pittsburgh, PA 15213-3890

9. SPONSORING / MONITORING AGENCY NAME(S) AND ADDRESS(ES)

10. SPONSOR/MONITOR'S ACRONYM(S)

11. SPONSOR/MONITOR'S REPORT NUMBER(S)

\section{DISTRIBUTION / AVAILABILITY STATEMENT}

Approved for public release; distribution is unlimited.

\section{SUPPLEMENTARY NOTES}

\section{ABSTRACT}

This report introduces Bayesian networks and describes how they can be used to model dredging decisions when uncertainties are present. Bayesian networks are efficient representations of joint probability distributions that can be used to perform statistical inference over a large number of random variables. An example application is developed and presented for a realistic estuarine dredging decision problem to demonstrate the method. The decision model is applied to analyze the value of obtaining additional information about selected variables that are sources of uncertainty in the decision.

\section{SUBJECT}

Bayesian networks

Decision problem

16. SECURITY CLASSIFICATION OF:

\begin{tabular}{|c|c|}
\hline a. REPORT & b. ABSTRACT \\
UNCLASSIFIED & UNCLASSIFIED \\
\hline
\end{tabular}

Joint probability distributions

Modeling dredging decisions

\begin{tabular}{l} 
17. LIMITATION \\
OF ABSTRACT \\
\hline
\end{tabular}

Statistical inference

Value of Information Analysis

\begin{tabular}{c|l}
\begin{tabular}{c|c} 
18. NUMBER \\
OF PAGES
\end{tabular} & $\begin{array}{l}\text { 19a. NAME OF RESPONSIBLE } \\
\text { PERSON }\end{array}$ \\
\cline { 2 - 2 } 74 & $\begin{array}{l}\text { 19b. TELEPHONE NUMBER (include } \\
\text { area code) }\end{array}$ \\
\hline
\end{tabular}

